\title{
Assembly of novel, nuclear dimers of the PI3-Kinase regulatory subunits underpins the pro-proliferative activity of the Cdc42- activated tyrosine kinase, ACK
}

Natasha S. Clayton ${ }^{1 \dagger}$, Millie Fox ${ }^{1 \dagger}$, Jose J. Vicenté-Garcia ${ }^{1 \dagger}$, Courtney M. Schroeder $^{1 \S}$, Trevor D. Littlewood ${ }^{1}$, Jonathan I. Wilde ${ }^{2 \uparrow}$, Jessica Corry ${ }^{1}$, Kadalmani Krishnan ${ }^{1 \#}$, Qifeng Zhang ${ }^{3}$, Michael J. O. Wakelam ${ }^{3}$, Murray J. B. Brown $^{2}$, Claire Crafter ${ }^{4}$, Helen R. Mott ${ }^{* *}$ and Darerca Owen ${ }^{1^{*}}$

${ }^{1}$ Department of Biochemistry, University of Cambridge, 80 Tennis Court Road, Cambridge, CB2 1GA, U.K.

${ }^{2}$ GlaxoSmithKline Medicines Research Centre, Gunnels Wood Rd., Stevenage, Herts, SG1 2NY, U.K.

${ }^{3}$ The Babraham Institute, Babraham Research Campus, Cambridge, CB22 3AT, U.K.

${ }^{4}$ Bioscience, Research and Early Development, Oncology R\&D, AstraZeneca, Cambridge, U.K.

*Corresponding authors: Darerca Owen, Tel: +44 1223 764824; e-mail: do202@cam.ac.uk, Helen Mott, Tel:+44 1223 764825; e-mail: hrm28@cam.ac.uk

${ }^{\dagger}$ These authors contributed equally to this work

"Present address: School of Cellular and Molecular Medicine, Biomedical Sciences Building, University Walk, Bristol, BS8 1TD, U.K.

Present address: GlaxoSmithKline, Stockley Park West, 1-3 Ironbridge Road, Uxbridge, Middlesex, UB11 1BT, U.K.

${ }^{\S}$ Present address: Division of Basic Sciences, Fred Hutchinson Cancer Research Center, 1100 Fairview Ave. N., Seattle, WA 98109 U.S.A.

'Present address: Veracyte, Suite 300, 6000 Shoreline Court, South San Francisco, CA 94080, U.S.A.

"Present address: Levim Biotech, 501-506, TICEL Biopark Phase II, CSIR Road, Taramani, Chennai 600 113. India

Running title: Regulation of the PI3-Kinase regulatory subunits by ACK 
Regulation of the PI3-Kinase regulatory subunits by ACK

\begin{abstract}
The tyrosine kinase ACK is an oncogene associated with poor prognosis in human cancers. ACK promotes proliferation, in part, by contributing to the activation of Akt, the major PI3-Kinase effector. We show that ACK also regulates PI3-Kinase directly, via interactions with the PI3-Kinase regulatory subunits. ACK interacts with all five regulatory subunit isoforms and directly phosphorylates $\mathrm{p} 85 \alpha, \mathrm{p} 85 \beta, \mathrm{p} 55 \alpha$ and $\mathrm{p} 50 \alpha$ on Tyr607 (or equivalent). Phosphorylation of p85 $\beta$ at this residue promotes cell proliferation but, counterintuitively, ACK does not stimulate PI3-Kinase catalytic activity. We show that ACK stabilizes p $85 \alpha$ levels by promoting an interaction between the $\mathrm{p} 85 \mathrm{nSH} 2$ domain and pTyr607, protecting $\mathrm{p} 85$ from ubiquitination. We demonstrate that ACK interacts with p $85 \alpha$ exclusively in nuclear-enriched cell fractions where the increased levels of the regulatory subunits, together with the $\mathrm{nSH} 2-\mathrm{pTyr} 607$ interaction, promote formation of dimeric $\mathrm{p} 85$. We postulate that these novel dimers undertake nuclear functions that contribute to Cdc42-ACK driven oncogenesis. We propose that ACK shapes PI3-Kinase signalling by dampening the $\mathrm{PIP}_{3}$ response, whilst continuing to drive cell proliferation through Akt activation and hereto unexplored but crucial functions of nuclear dimeric $\mathrm{p} 85$. These new regulatory subunit dimers represent a previously undescribed mode of regulation for PI3-Kinase and potentially reveal additional avenues for therapeutic intervention.
\end{abstract}




\section{Introduction}

The small $\mathrm{G}$ protein Cdc42 controls the formation of filopodia by initiating actin remodelling and this process is vital to cell motility. Cdc42 often signals downstream of the master regulator small $\mathrm{G}$ protein, Ras, and $\mathrm{Cdc} 42$ deregulation results in the progression of several disease states, including tumour metastasis (1). Genetic deletion of CDC42 in Ras-transformed cells results in reductions in cell proliferation and cell cycle progression, demonstrating the requirement for Cdc42 in Ras-induced transformation (2). Accordingly, overexpression of Cdc42 is seen in several human cancers and is correlated with poor disease outcome (3-5). Although mutations in Cdc42 are rarely observed in human cancers, oncogenic mutations have been characterised in its regulators such as the GEFs Dbl (6) and Asef2 (7) and the GAP DLC1 (8), all of which act to increase the basal level of Cdc42 GTP contributing to cellular transformation. Cdc42 participates in both physiological and tumorigenic processes by interacting with effector proteins including the non-receptor tyrosine kinase, activated Cdc42-associated kinase (ACK) (9).

ACK is a ubiquitously expressed non-receptor tyrosine kinase first identified as an effector for Cdc42 (9). The N-terminus of the $120 \mathrm{kDa}$ ACK protein comprises a sterile alpha motif (SAM) domain, nuclear export signal (NES), tyrosine kinase domain, Src homology-3 (SH3) domain and a Cdc42/Rac-interactive binding (CRIB) motif. The proline-rich C-terminus of ACK includes a clathrin binding region, an epidermal growth factor (EGF) receptor-binding domain (EBD) and a ubiquitin association domain (UBA) (Figure 1A).

In the past decade, ACK has emerged as a prospective therapeutic target in multiple human cancers. A genomic study, which sought to identify oncogenic 'driver' mutations within the protein kinase gene family in 210 diverse cancers, identified four such mutations in ACK (10), ranking ACK within the top 5\% of kinases driving cancer. Amplification or mutation of the gene encoding ACK is common in aggressive lung, ovarian and hormone refractory prostate tumours, and increased levels of ACK mRNA correlate with poor patient prognosis $(10,11)$. Expression of activated ACK in LNCaP cells increases the ability of the cells to form tumours in nude mice (12). Ultimately, the successful development of therapeutic inhibitors that down-regulate ACK signalling will rely on a detailed understanding of the pathways that feed into ACK activation and the pathways that are activated downstream of ACK.

Although ACK is implicated in tumourigenesis, relatively little is known about its cellular substrates or interacting proteins, leaving the full molecular details of its function unknown. Headway has been made in understanding the role of ACK in prostate cancer. ACK phosphorylates the tumour suppressor Wwox, leading to its ubiquitination and degradation in the later stages of prostate cancer progression (12). ACK also phosphorylates histone H4, which ultimately leads to up-regulation of the Androgen Receptor (AR) (13) and, in a co-ordinated manner, ACK phosphorylates the AR directly, activating its transcriptional activity (14). Both activities contribute to progression to the castration-resistant phase of prostate cancer.

We have identified the class Ia PI3-Kinase regulatory subunit isoforms as novel ACK interacting proteins. PI3-Kinases catalyse the formation of the second messenger $\mathrm{PIP}_{3}$ 
from $\mathrm{PIP}_{2}$, which leads to the activation of pathways that promote cell proliferation and survival. Class Ia PI3-Kinases consist of a catalytic subunit (p110), of which there are three isoforms ( $110 \alpha, \beta$ and $\delta)$, bound to a regulatory subunit (p85), which exists in five isoforms: $\mathrm{p} 85 \alpha, \mathrm{p} 85 \beta, \mathrm{p} 55 \alpha, \mathrm{p} 50 \alpha$ and $\mathrm{p} 55 \gamma$. The five regulatory isoforms have a similar domain organisation at the $\mathrm{C}$-terminus (Figure $1 \mathrm{~B}$ ), with a proline rich sequence and two Src homology-2 (SH2) domains, separated by a coiled-coiled domain termed the inter-SH2 (iSH2) region. The larger regulatory subunit isoforms, $\mathrm{p} 85 \alpha$ and $\mathrm{p} 85 \beta$, also possess additional functional domains at the N-terminus, including a Src homology-3 (SH3) domain, proline-rich sequences and a RhoGAP domain (often referred to as the $\mathrm{BH}$ domain), which shows sequence homology to the GTPase-activating protein (GAP) domain of the breakpoint cluster region protein, Bcr. p1 $10 \alpha$ is the most commonly mutated kinase in the human genome (15) and cancer-associated mutations or alterations in gene copy number have been identified for the genes encoding each of the three catalytic subunit isoforms (PIK3CA, PIK3CB and $P I K 3 C D)$ and the genes encoding each of the five regulatory subunit isoforms (PIK3R1, PIK3R2 and PIK3R3) (16). In fact PI3KR1 is the $11^{\text {th }}$ most mutated gene across a subset of 20 human cancers (17). Over-activation of PI3-Kinase signalling in cancer can also result from mutations that reduce the activity of the PTEN phosphatase, which counteracts PI3-Kinase activity by dephosphorylating $\mathrm{PIP}_{3}$ back to $\mathrm{PIP}_{2}$, or from mutations that activate the major downstream effector kinase, Akt.

ACK also modulates PI3-kinase signalling pathways by directly phosphorylating Akt, which promotes Akt membrane localization and subsequent phosphorylation, resulting in its activation (18). Here, we report that ACK interacts with other key components of the PI3-Kinase pathway, the PI3-Kinase regulatory subunits. ACK interacts with all five regulatory subunits of PI3K, phosphorylating four of them in the iSH 2 region. This $\mathrm{pTyr}$ serves to stabilise $\mathrm{p} 85$ by preventing ubiquitination and proteasome degradation, leading to increased cellular levels of the regulatory subunits. The mechanism underpinning this stabilization involves an interaction between the pTyr and the $\mathrm{nSH} 2$ domain of the regulatory subunit. This interaction in trans supports formation of a novel dimeric form of $\mathrm{p} 85$, which is favoured due to increased levels of the regulatory isoforms, leading to a pool of $\mathrm{p} 110$-free $\mathrm{p} 85$. This new mechanism of dimerization mediated by sites in the C-terminal regions of the p85 isoforms is also possible in the shorter isoforms, permitting multiple homo and hetero dimer combinations. We further demonstrate that the interaction between ACK and p85 occurs exclusively in the nucleus, where the resulting phosphodimers are also mainly located.

We show that the proliferative advantage conferred by ACK is driven, at least in part, by its effects on the regulatory subunits and propose that ACK modulates the PI3Kinase response at multiple nodes including hereto unexplored but crucial functions of novel C-terminally mediated $\mathrm{p} 85$ dimers in the nucleus. These new regulatory subunit dimers represent a previously unidentified mode of regulation for PI3-Kinase and potentially reveal additional avenues for therapeutic intervention. 
Regulation of the PI3-Kinase regulatory subunits by $A C K$

\section{Materials and Methods}

\section{Yeast-2-hybrid screen}

ACK (1-489) was cloned into pENTR/D-TOPO and then transferred into destination vectors GpYTH9 and GpYTH16, using Gateway recombination. This produced recombinant yeast expression bait constructs with the ACK coding region in frame with the DNA binding domain of Gal4. The GpYTH16 construct was used to assess trans-activation in $S$. cerevisiae using a $\beta$-galactosidase assay, while the GpYTH9 construct was linearized with $X b a 1$ and integrated into the yeast strain Y190::ADE2 (MATa, ura3-52, his3- $\Delta 200$, lys2-801, trp1-901, leu2-3, 112, gal4 $\Delta$, gal80 $\Delta$, cyh ${ }^{\mathrm{r}} 2$, LYS2::GAL1 ${ }_{\text {UAS }}-H I S 3_{\text {TATA }}-H I S 3$, MEL1 URA3::GAL UAS-GAL1 ${ }_{\text {TATA }}$-lacZ, GAL2 UAS-GAL2 TATA-ADE2 ) for screening. Transformants were selected on media lacking tryptophan. The resulting strain was transformed with a Matchmaker Human Foetal Brain cDNA library (Clontech), where prey cDNAs are cloned in frame with the activation domain of Gal4 in pACT2. Transformants were selected on media lacking leucine but containing X-gal (5-Bromo-4-Chloro-3-Indolyl $\beta$-D-Galactopyranoside). Large blue colonies were picked onto fresh selective plates and then reassayed for $\beta$ galactosidase activity. Yeast colonies were transferred onto Whatman No.54 filter papers and lysed by freeze thawing. Each filter was then immersed in $60 \mathrm{mM}$ $\mathrm{NaH}_{2} \mathrm{PO}_{4}, 40 \mathrm{mM} \mathrm{NaH}_{2} \mathrm{PO}_{4}, 10 \mathrm{mM} \mathrm{KCl}, 0.1 \mathrm{mM} \mathrm{MgSO}_{4}, 40 \mathrm{mM} \beta-$ mercaptoethanol, $1 \mathrm{mg} / \mathrm{mL} \mathrm{X-gal,} \mathrm{pH} 7.0$ and incubated at $37^{\circ} \mathrm{C}$ for $4 \mathrm{~h}$. Filters were air-dried and checked for blue colouration. Library plasmids isolated from the $\beta$ galactosidase-expressing $\mathrm{Leu}^{+}$yeast, were recovered and their sequences analysed.

\section{Plasmids and site-directed mutagenesis}

pXJ-HA-ACK was a kind gift from Prof Ed Manser (ICMB, Singapore). Full-length human $\mathrm{p} 85 \alpha, \mathrm{p} 50 \alpha, \mathrm{p} 55 \alpha$ and $\mathrm{p} 55 \gamma$ and mouse p85 $\beta$ cDNA (IMAGE) were amplified by PCR, cloned into $\mathrm{pENTR/D-TOPO}$ and then transferred into the mammalian expression vector $\mathrm{pDEST} 12.2-\mathrm{FLAG}$ and the bacterial expression vectors $\mathrm{pDEST} 15$ and pETG-41A using Gateway technology. p $85 \beta$ cDNA was also cloned into the lentiviral vector, pSLIK-hygro. The coding sequences of wt and caACK were digested from $\mathrm{pXJ}-\mathrm{HA}$ constructs $E c o \mathrm{RI} / X h o \mathrm{I}$ and ligated into the retroviral expression vector, pBABE-puro. Site-directed mutagenesis was performed using a QuikChange Lightning Multi Site-Directed Mutagenesis Kit (Agilent Technologies).

\section{Antibodies}

The following antibodies were used for immunoblotting: anti-FLAG-HRP (A8592, Sigma Aldrich), anti-V5 (46-0705, Invitrogen) and anti-GST (27-4577-01, GE Healthcare); anti-p-Tyr-HRP (sc-7020), anti-p85 (sc-423), anti-Hsp56 (sc-1803), antiGAPDH (sc-47724) and anti-HA-HRP (sc-7392) were purchased from Santa Cruz Biotechnology; anti-ACK (161-175 and 07-757) and anti-ACK p-Tyr284 (09-142) were purchased from Millipore; anti-Histone H3 (ab1791) and anti-pY607 p85 (ab182651) were purchased from Abcam. The HRP-conjugated secondary antibodies donkey anti-mouse (sc-2318) and donkey anti-rabbit (sc-2317) were purchased from Santa Cruz Biotechnology. Anti-FLAG (F3165, Sigma Aldrich) was used for immunoprecipitation. 
Regulation of the PI3-Kinase regulatory subunits by ACK

\section{Cell Lines}

HEK293T cells were cultured in DMEM supplemented with 10\% FBS and transfected using Lipofectamine 2000. To generate HEK293T cell lines stably expressing HA-wtACK or HA-caACK, Phoenix-AMPHO cells were transfected with pBABE-puro-wtACK or caACK. Retroviral supernatant was collected after $72 \mathrm{~h}$ and added to HEK293T cells for $16 \mathrm{~h}$ with $4 \mathrm{ng} / \mu \mathrm{L}$ polybrene. Infected cells were selected using $1 \mu \mathrm{g} / \mathrm{mL}$ puromycin dihydrochloride. To generate HEK293T cell lines stably expressing FLAG-wt p85 $\beta / \mathrm{p} 85 \beta$ Y 599F, HEK293T cells were transfected with $8 \mu \mathrm{g}$ pSLIK-hygro-FLAG-wt $\mathrm{p} 85 \beta / \mathrm{p} 85 \beta$ Y $599 \mathrm{~F}$ and $4 \mu \mathrm{g}$ each of the packaging vectors pCMV-VSV-G and pCMV- $\triangle \mathrm{R} 8.2 \mathrm{dvpr}$. After $16 \mathrm{~h}$, viral supernatant was added to recipient HEK293T cells for $16 \mathrm{~h}$ with $4 \mathrm{ng} / \mu \mathrm{L}$ polybrene. Infected cells were selected using $150 \mu \mathrm{g} / \mathrm{mL}$ Hygromycin B. Transgene expression was confirmed by immunoblotting. Control cell lines were generated in the same way using empty vector but were expanded as a polyclonal cell line.

\section{Cell Proliferation Assays}

Cells were seeded into 6-well plates at a density of $3 \times 10^{4}$ cells per well and incubated at $37{ }^{\circ} \mathrm{C}, 5 \% \mathrm{CO}_{2}$. Assays using ACK stable cell lines were performed in DMEM + $0.5 \%$ FBS. Assays using p $85 \beta$ cell lines were performed in DMEM $+10 \%$ FBS. p $85 \beta$ expression was induced using $1 \mathrm{mg} / \mathrm{mL}$ doxycycline. Cells were trypsinized and dispersed using a syringe before being counted using a Countess automated cell counter at specific timepoints.

\section{Co-immunoprecipitation}

Small-scale co-immunoprecipitations were performed using $1 \mu \mathrm{g}$ antibody crosslinked to Protein G Dynabeads (Life Technologies) with dimethyl pimelimidate (DMP). HEK293T cells were grown in $10 \mathrm{~cm}$ dishes to $70 \%$ confluence and then transfected for $40 \mathrm{~h}$. Cells were then washed in cold PBS and lysed on ice in $500 \mu \mathrm{L}$ mammalian cell lysis buffer $(50 \mathrm{mM}$ Tris- $\mathrm{HCl} \mathrm{pH}$ 7.5, $150 \mathrm{mM} \mathrm{NaCl}, 1 \mathrm{mM}$ EDTA, $1 \mathrm{mM}$ sodium orthovanadate, $1 \mathrm{mM} \beta$-glycerophosphate disodium salt hydrate, $1 \mathrm{X}$ Mammalian Protease Inhibitor Cocktail (Sigma Aldrich, P8340), 1\% Triton X-100). Lysates were centrifuged at $17000 \mathrm{~g}$ for $20 \mathrm{~min}$ at $4{ }^{\circ} \mathrm{C}$ and supernatants were precleared by incubation with $50 \mu \mathrm{L}$ Dynabeads at $4{ }^{\circ} \mathrm{C}$ for $1 \mathrm{~h}$. Once cell lysates had pre-cleared, $500 \mu \mathrm{L}$ of each lysate was rotated with $50 \mu \mathrm{L}$ antibody-bound beads for 1 $\mathrm{h}$. The beads were then washed three times with mammalian cell lysis buffer and protein complexes were eluted using $20 \mu \mathrm{L} 2 \mathrm{X}$ LDS sample buffer (Life Technologies) mixed with $20 \mu \mathrm{L}$ PBS.

\section{Immunoblotting}

Proteins were transferred to Immobilon-P PVDF membrane (Millipore) using an XCell IITM Blot Module (Life Technologies) following manufacturer's instructions. Membranes were blocked in 10\% milk dissolved in PBS- $0.1 \%$ Tween. Protein bands were visualized using enhanced chemiluminescence. 
Regulation of the PI3-Kinase regulatory subunits by $A C K$

\section{Cell fractionation}

Cells were grown in $10 \mathrm{~cm}$ dishes to $70 \%$ confluence and then transfected for $40 \mathrm{~h}$. Cells were then washed in PBS, resuspended and pelleted by centrifugation at $500 \mathrm{~g}$ for $20 \mathrm{~min}$ at $4{ }^{\circ} \mathrm{C}$. Cell pellets were then resuspended in $500 \mu \mathrm{L}$ cold hypotonic buffer (20 mM Tris- $\left.\mathrm{HCl} \mathrm{pH} 7.4,10 \mathrm{mM} \mathrm{NaCl}, 3 \mathrm{mM} \mathrm{MgCl}_{2}\right)$ and incubated on ice for $15 \mathrm{~min} .25 \mu \mathrm{L} \mathrm{NP}-40$ Alternative was then added and cells were lysed by vortexing for $10 \mathrm{sec}$. Samples were then centrifuged at $500 \mathrm{~g}$ for $20 \mathrm{~min}$ at $4{ }^{\circ} \mathrm{C}$ to separate the cytoplasmic fraction from intact nuclei and other subcellular structures. The supernatant (cytoplasmic fraction) was removed and stored on ice. The pellet was washed with $500 \mu \mathrm{L}$ cold hypotonic buffer and then resuspended in $500 \mu \mathrm{L}$ cell extraction buffer (100 mM Tris-HCl pH 7.4, $100 \mathrm{mM} \mathrm{NaCl}, 1 \mathrm{mM}$ EDTA, $1 \mathrm{mM}$ EGTA, 0.1\% SDS, $1 \mathrm{mM} \mathrm{NaF}, 2 \mathrm{mM} \mathrm{Na} \mathrm{VO}_{4}, 1 \%$ Triton $\mathrm{X}-100,10 \%$ glycerol, $0.5 \%$ deoxycholate, $20 \mathrm{mM} \mathrm{Na}_{4} \mathrm{P}_{2} \mathrm{O}_{7}, 1 \mathrm{mM}$ PMSF, $1 \mathrm{X}$ Mammalian Protease Inhibitor Cocktail. Pellets were incubated on ice for $30 \mathrm{~min}$ with vortexing every $10 \mathrm{~min}$. Insoluble debris was cleared from the nuclear-enriched fractions by sonication and centrifugation at $17000 \mathrm{~g}$ for $30 \mathrm{~min}$ at $4{ }^{\circ} \mathrm{C}$. Cytoplasmic and nuclear-enriched fractions were then either analysed by SDS-PAGE gel directly or used in coimmunoprecipitation studies.

\section{Quantification of PIP 3}

HEK293T cells were seeded onto 6-well plates at a density of $1 \times 10^{6}$ cells per well and incubated at $37^{\circ} \mathrm{C}, 5 \% \mathrm{CO}_{2}$ for $24 \mathrm{~h}$ before transfection with the appropriate construct for $24 \mathrm{~h}$. Cells were then serum starved for $16 \mathrm{~h}$ before stimulation with $10 \mathrm{nM}$ EGF for $5 \mathrm{~min}$. Cells were washed with ice cold PBS, harvested and frozen in liquid nitrogen. Phosphoinositides were extracted as previously described and samples were quantified for total cellular $\mathrm{PIP}_{3}$ and $\mathrm{PIP}_{2}$ by the mass spectrometry (19).

\section{Expression and purification of recombinant regulatory subunits and domains}

Full-length human $\mathrm{p} 85 \alpha, \mathrm{p} 50 \alpha, \mathrm{p} 55 \alpha$, mouse p85 $\beta$, p85 $\alpha$ nSH2 (325-430), p85 $\alpha$ cSH2 (614-720) and p85 $\beta$ cSH2 (603-712) were expressed in E. coli as GST fusion proteins. Expression was induced by $1 \mathrm{mM} \mathrm{IPTG}$ for $16 \mathrm{~h}$ at $20^{\circ} \mathrm{C}$. Cells were harvested and resuspended in MTPBS $\left(150 \mathrm{mM} \mathrm{NaCl}, 16 \mathrm{mM} \mathrm{Na}_{2} \mathrm{HPO}_{4}, 4 \mathrm{mM}\right.$ $\mathrm{NaH}_{2} \mathrm{PO}_{4} \mathrm{pH}$ 7.3) supplemented with SIGMAFAST Protease Inhibitor Cocktail Tablet (EDTA-free) and $1 \mathrm{mM}$ PMSF, and lysed using an Emulsiflex at 10000 p.s.i. Lysates were centrifuged at $18000 \mathrm{~g}$ for $40 \mathrm{~min}$ at $4{ }^{\circ} \mathrm{C}$ and the supernatant applied to glutathione-agarose beads for $2 \mathrm{~h}$ at $4{ }^{\circ} \mathrm{C}$. After washing, GST-full-length p85 fusion proteins were eluted from the beads with $10 \mathrm{mM}$ reduced glutathione. GST-SH2 fusion proteins were subject to HRV 3C cleavage whilst immobilized on GST beads in MTPBS, $1 \mathrm{mM}$ DTT, $1 \mathrm{mM}$ EDTA. Following cleavage, the SH2 domains were further purified by size exclusion chromatography on an S75 column (GE Healthcare).

Full-length human $\mathrm{p} 55 \gamma$ and $\mathrm{p} 85 \beta \mathrm{nSH} 2$ (312-425) were expressed as fusion proteins with $\mathrm{N}$-terminal $\mathrm{His}_{6}$ and MBP tags. Expression of $\mathrm{p} 55 \gamma$ fusion protein was induced with $1 \mathrm{mM}$ IPTG for $3 \mathrm{~h}$ at $30^{\circ} \mathrm{C}$. Expression of $\mathrm{p} 85 \beta \mathrm{nSH} 2$ fusion protein was induced with $1 \mathrm{mM}$ at $37^{\circ} \mathrm{C}$ for $5 \mathrm{~h}$. Cell pellets were resuspended in lysis buffer $(20$ $\mathrm{mM}$ Tris- $\mathrm{HCl} \mathrm{pH}$ 7.9, $500 \mathrm{mM} \mathrm{NaCl}$ ) supplemented with Protease Inhibitor Cocktail (Sigma Aldrich, S8830) and $1 \mathrm{mM}$ PMSF. Cells were lysed as described above. 
Cleared lysate was loaded onto a Ni-NTA column and proteins eluted using and imidazole gradient. $\mathrm{His}_{6}-\mathrm{MBP}-\mathrm{p} 85 \beta \mathrm{nSH} 2$ fusion was subject to HRV $3 \mathrm{C}$ cleavage and further purification by size exclusion chromatography as described previously.

\section{Expression and purification of His6-ACK (110-489) and GST-ACK (1-489)}

ACK residues 110-489 were cloned into pFastBac-HT and recombinant bacmid was generated, using E. coli DH10Bac, to allow expression of $\mathrm{His}_{6}$-ACK (110-489) using the baculovirus/Sf9 cell system. ACK residues 1-489 were cloned into pDEST15 using Gateway technology. GST-ACK (1-489) was expressed in BL21 Rosetta 2(DE3) cells. His 6 -ACK (110-489) and GST-ACK (1-489) were purified as previously described (20).

\section{In vitro kinase assays}

His $_{6}$-ACK (110-489) or GST-ACK (1-489) was incubated for $10 \mathrm{~min}$ at $30^{\circ} \mathrm{C}$ in kinase buffer (20 mM Tris-HCL pH 7.5, $10 \mathrm{mM} \mathrm{MgCl}_{2}, 0.5 \mathrm{mM}$ DTT, $0.1 \mathrm{mM}$ sodium orthovanadate) supplemented $0.5 \mathrm{mM} \mathrm{ATP} \mathrm{pH} 7.5$ to promote autophosphorylation. For in vitro kinase assays, $0.3 \mathrm{mM}$ autophosphorylated His $_{6}$ ACK (110-489) or GST-ACK (1-489) was added to kinase buffer with $30 \mathrm{mM}$ substrate in a final reaction volume of $50 \mu \mathrm{L}$ and incubated for $30 \mathrm{~min}$ at $30^{\circ} \mathrm{C}$.

\section{Phosphorylation site mapping using LC-MS/MS}

Samples were resolved by SDS-PAGE and visualized using InstantBlue (Expedeon). Bands of interest were excised from the gel, destained, reduced using DTT and alkylated using iodoacetamide. The protein was then digested with trypsin overnight at $37^{\circ} \mathrm{C}$ and then loaded onto a nanoAcquity UPLC (Waters Corp., Milford, MA) system and an LTQ Orbitrap Velos hybrid ion trap mass spectrometer (Thermo Scientific, Waltham, MA) for analysis. The peptides were first separated by reversephase liquid chromatography (LC) using a Waters reverse-phase nano column (BEH C18, $75 \mathrm{~mm}$ i.d. x $250 \mathrm{~mm}, 1.7 \mathrm{~mm}$ particle size) at flow rate of $300 \mathrm{~nL} / \mathrm{min}$ after preloading onto a pre-column (Waters UPLC Trap Symmetry C18, $180 \mathrm{~mm}$ i.d. x 20 $\mathrm{mm}, 5 \mathrm{~mm}$ particle size) in $0.1 \%$ formic acid for $5 \mathrm{~min}$ at a flow rate of $5 \mathrm{~mL} / \mathrm{min}$. The peptides were then eluted from the pre-column and loaded onto the nanoAcquity analytical column. The LC eluant was sprayed into the mass spectrometer using a New Objective nanospray source. The $\mathrm{m} / \mathrm{z}$ values of eluting ions were measured in the Orbitrap Velos mass analyzer, set at a resolution of 30000 . Data dependent scans (top 20) were then employed to automatically isolate and generate fragment ions by collision-induced dissociation in the linear ion trap, resulting in the generation of $\mathrm{MS} / \mathrm{MS}$ spectra. Ions with charge states of $2+$ and above were selected for fragmentation. The MS/MS data were processed using Protein Discoverer (version 1.3, ThermoFisher). Briefly, all MS/MS data files were submitted to the Mascot search algorithm (Matrix Science, London UK) and searched against the PI3-Kinase regulatory subunit 1 sequence, using a fixed modification of carbamidomethyl and variable modifications of oxidation (M) and phospho (Ser,Thr,Tyr). Sites of phosphorylation were then verified manually. The peptide and fragment mass tolerances were set to $25 \mathrm{ppm}$ and $0.8 \mathrm{Da}$, respectively. A significance threshold value of $p<0.05$ and a peptide cut-off score of 20 were also applied. 
Regulation of the PI3-Kinase regulatory subunits by $A C K$

\section{Fluorescent Polarization Assays}

p85 $\alpha$ and CD28 peptides were purchased from Biomatik; $p 85 \beta$ peptides were purchased from Cambridge Research Biochemicals. Peptide sequences were as follows: peptides based on p85 $\alpha$, [5-FAM]-TEDQ-[pY]-SLVEDE and [5-FAM]TEDQYSLVEDE; peptides based on p85 $\beta$, [5-FAM]-TEDQ-[pY]-SLMEDE and [5FAM]-TEDQYSLMEDE; CD28 peptide, [5-FAM]-SD-[pY]-MNMTP. Fluorescence polarization experiments were measured on a BMG Labtech Pherastar fluorimeter at $298 \mathrm{~K}$ with excitation $485 \mathrm{~nm}$ and emission $520 \mathrm{~nm}$. Solutions were made up in black flat-bottom 384 well plates (Corning) to a final volume of $30 \mu \mathrm{L}$. A peptide titration was used to determine the appropriate concentration of peptide for binding assays. CD28, p85 $\alpha$ and phospho-p85 $\alpha$ were used at 20nM. p85 $\beta$ and phospho-p85 $\beta$ were used at a final concentration of $40 \mathrm{nM}$. Anisotropy was calculated from polarization measurements in MARS analysis software and data fitted to a single site binding isotherm in Prism. 


\section{Results}

\section{Identification of the interaction between $\mathrm{ACK}$ and the PI3-Kinase regulatory subunits}

A yeast-2-hybrid screen was performed to identify binding partners for ACK. A yeast strain, containing integrated GpYTH16-ACK(1-489) as bait, was screened against a pACT2-based human adult brain cDNA library, expressing prey proteins fused to the GAL4 activation domain. A human brain library was chosen as ACK was initially isolated from a human hippocampal expression library (9) and, although ACK is ubiquitously expressed, it shows high expression levels in the brain (21). $169 \beta$ galactosidase positive colonies were obtained, of which 114 remained after rescreening. Sequence analysis of the positive colonies revealed three isoforms of the PI3-Kinase regulatory subunit, $\mathrm{p} 85 \alpha, \mathrm{p} 85 \beta$ and $\mathrm{p} 55 \gamma$, as the top hits for putative, novel ACK interacting proteins.

The yeast-2-hybrid screen detected an interaction between the N-terminal half of ACK (1-489) and p85 $\alpha$ (479-724), p85 $\beta$ (342-728) and p55 (120-461) (Figure 1A and $\mathrm{B}$ ), all of which included the C-terminal SH2 domain and most of the inter-SH2 region. The p85 $\alpha$ splice variants, $\mathrm{p} 50 \alpha$ and $\mathrm{p} 55 \alpha$, were not identified in the screen but as they both contain the $\mathrm{C}$-terminal $\mathrm{SH} 2$ domain and inter-SH2 region, we reasoned that ACK would likely interact with these isoforms as well. Co-expression of fulllength ACK with all five full-length p85 isoforms individually in HEK293T cells, followed by immunoprecipitation, revealed that ACK could interact with all regulatory subunit isoforms (Figure $2 \mathrm{~A}-\mathrm{E}$ ). Isoforms $\mathrm{p} 85 \alpha, \mathrm{p} 85 \beta$ and $\mathrm{p} 55 \gamma$ were also found to interact with a kinase-dead ACK mutant, dACK (K158R) (Figure 2A, D and E), suggesting that catalytic activity was not required for these novel interactions.

\section{ACK phosphorylates p85 $\alpha, p 85 \beta, p 55 \alpha$ and p50 $\alpha$ at a conserved tyrosine within the iSH2 region}

After confirming all five PI3-Kinase regulatory subunits as ACK binding partners, we next examined whether they were also ACK substrates. Several potential phosphotyrosine sites have been identified in the iSH2-cSH2 ACK-interacting region: one of these, Tyr607 (p85 $\alpha$ numbering) within the iSH2, is reported to be a major phosphorylation site on p85 $\alpha$ for the insulin receptor (22). Using an anti-p85 pTyr607 antibody, we found that $\mathrm{p} 85 \alpha, \mathrm{p} 55 \alpha$ and $\mathrm{p} 85 \beta$ were phosphorylated on Tyr607, or the equivalent tyrosine residue, when they were co-expressed with ACK but not with dACK (Figure 3A, B and D). Phosphorylation at this site in p50 $\alpha$ (Tyr307) could not be detected, however, immunoblotting with a pan anti-pTyr antibody indicted that p50 $\alpha$ did show increased tyrosine phosphorylation in the presence of ACK but not dACK (Figure 3C).

It was not possible to determine whether p55 $\gamma$ was phosphorylated on Tyr341 (equivalent to Tyr607 in p85 $\alpha$ ) when co-expressed with ACK using the anti-p85 pTyr607 antibody, as p55 $\gamma$ does not possess the motif (D-Q-Y $\left.{ }_{(\mathrm{p})}-\mathrm{S}-\mathrm{L}\right)$ recognized by this antibody (Figure 3F). However the change in sequence context around this Tyr in p55 $\gamma$ also implied that it was unlikely to be phosphorylated by ACK. Immunoblotting with a pan anti-pTyr antibody was used to assess whether p55 $\gamma$ showed increased tyrosine phosphorylation when co-expressed with ACK in cells. The signal from the 
pan anti-pTyr antibody at $55 \mathrm{kDa}$ was no stronger in the lysate co-expressing p55 and ACK than lysate co-expressing p55 $\gamma$ with dACK (Figure 3E), suggesting that p55 $\gamma$ is not a substrate for ACK.

To confirm that phosphorylation on Tyr607 by ACK was direct, in vitro kinase assays were performed using a purified, recombinant, active fragment of ACK. This was used to phosphorylate full-length regulatory subunit isoforms purified from E. coli. Incubation of GST-tagged p85 $\alpha, \mathrm{p} 85 \beta$, p $55 \alpha$ and p $50 \alpha$ with ACK resulted in their direct phosphorylation on Tyr607 (or equivalent), as assessed by immunoblotting (Figure 4A-D).

To investigate whether ACK phosphorylates the regulatory subunits at additional tyrosine residues, the in vitro kinase assay using GST-p50 $\alpha$ and ACK was repeated, resolved by gel electrophoresis and the phosphorylation site(s) mapped by mass spectrometry. Comparison of the mass spectra of samples with and without ACK detected phosphorylation of Tyr307 p50 $\alpha$ (equivalent to Tyr607 in p85a) only when ACK was present (Figure S1). No other tyrosine phosphorylation sites were identified, indicating that ACK phosphorylates p50 $\alpha$ only at Tyr307 in vitro. To confirm that $555 \gamma$ was not an ACK substrate, His 6 -MBP-p55 $\gamma$ was incubated with ACK and phosphorylation sites were mapped by LC-MS/MS. No increase in p55 $\gamma$ tyrosine phosphorylation was detected following incubation with ACK, corroborating the results obtained in HEK293T cells.

\section{Phosphorylation of p85 $\beta$ by ACK promotes cell proliferation}

Tyr607 (or equivalent) is located within the inter-SH2 region of the regulatory subunits (Figure 1B). The inter-SH2 region is known to provide important regulatory contacts with the PI3-Kinase catalytic subunit (23) and insulin receptor activation results in phosphorylation at this site in vivo (22). We hypothesized that phosphorylation of the regulatory subunits by ACK within this functionally significant region would lead to an increase in PI3-Kinase catalytic activity, which could in part mediate the increase in cell proliferation that has been observed following overexpression of constitutively active ACK (caACK) in cells in culture (12). To investigate this, HEK293T cell lines were generated which stably expressed wild type (wt) ACK, caACK, wt p85 $\beta$ or a non-phosphorylatable p $85 \beta$ mutant, Y599F (equivalent to Tyr607 in p85 $\alpha$ ). Several lines were analyzed for equivalent protein expression levels and then tested for comparative rates of proliferation. Proliferation assays confirmed that the introduction of either wt or caACK into HEK293T cells conferred a proliferative advantage (Figure 5A). Cells expressing wt $\mathrm{p} 85 \beta$ grew at a slower rate than control cells (Figure 5B) demonstrating that $\mathrm{p} 85 \beta$ inhibits proliferation. This is in agreement with previous studies that indicate increased levels of p85 negatively regulate PI3-Kinase activity $(24,25)$. Cells expressing Y599F p $85 \beta$ however, proliferated at an even slower rate suggesting that the inhibitory effect of $\mathrm{p} 85 \beta$ is counteracted by phosphorylation at Tyr599. The effects of the ACK specific inhibitor AIM-100 (26) were also tested. Cells expressing wt p $85 \beta$ grew at a reduced rate in the presence of AIM-100 (Figure 5B), suggesting that phosphorylation at Tyr599 by endogenous ACK counteracts some of the antiproliferative effects of $\mathrm{p} 85 \beta$, while no effect was seen for cells expressing Y $599 \mathrm{~F}$ p $85 \beta$ in the presence of AIM-100. Overall these data suggest that ACK stimulates cell proliferation by phosphorylating p85 $\beta$ at Tyr599. 


\section{ACK suppresses increases in PIP $_{3}$ following EGFR activation}

We rationalized that phosphorylation of the regulatory subunits might increase the catalytic activity of PI3-Kinase by modulating the interaction between the regulatory and catalytic subunits. Mass spectrometry was used to quantify levels of $\mathrm{PIP}_{3}$ directly in cells that had been transfected with ACK. To quantify total cellular $\mathrm{PIP}_{3}$, cellular phosphoinositides were extracted from HEK293T cells and derivatized (19). Extracts were then analysed by high-performance liquid chromatography-mass spectrometry. To assess whether ACK affects basal and/or EGF-stimulated PIP ${ }_{3}$ levels in HEK293T cells, cells were transfected with constructs expressing wtACK or caACK. After 24 hours, cells were serum starved and then treated with EGF to stimulate $\mathrm{PIP}_{3}$ production. Whilst control (GFP) transfected cells showed an increase in $\mathrm{PIP}_{3}$ following EGF stimulation, this was not observed in cells transfected with wtACK (Figure 6), suggesting that ACK actually suppresses the PI3-Kinase response to EGF stimulation. Consistent with this, expression of caACK decreased levels of $\mathrm{PIP}_{3}$ following EGF treatment (Figure 6). These data suggest that ACK either suppresses the generation of $\mathrm{PIP}_{3}$ or promotes $\mathrm{PIP}_{3}$ clearance, effects that are likely to be dependent on ACK kinase activity. Moreover the data suggest that stimulation of cell proliferation by phosphorylation of $\mathrm{p} 85$ at Tyr607 by ACK is not mediated through an increase in PI3-Kinase lipid kinase activity but by an alternative mechanism.

\section{Stabilization of p85 by ACK}

There is considerable evidence that increased levels of cellular $\mathrm{p} 85 \alpha$ and $\mathrm{p} 85 \beta$ result in inhibition of PI3-Kinase activity $(27,28)$. The mechanism through which this inhibition is achieved is not clear, although it has been suggested that $\mathrm{p} 110$-free $\mathrm{p} 85$ could compete with PI3-Kinase heterodimers for binding to phosphotyrosine motifs on activated RTKs (28). To investigate whether ACK increases the levels of $p 85 \alpha / \beta$ in HEK293T cells by stabilising the $p 85$ protein, levels of endogenous $p 85 \alpha / \beta$ in the presence and absence of transfected ACK were compared following treatment of cells with cycloheximide (Figure 7A). In the absence of exogenous ACK expression, endogenous $\mathrm{p} 85 \alpha / \beta$ levels are significantly reduced after cycloheximide treatment. This effect is not seen in cells that have been transfected with ACK, suggesting that the level of $\mathrm{p} 85$ in the cell is, at least in part, regulated by ACK-mediated stabilization.

To investigate whether the mechanism underpinning stabilization of $\mathrm{p} 85$ by ACK involves phosphorylation at Tyr607, HEK293T cells were transfected with wt p85 $\alpha$, p85 $\alpha$ Y 607D, a phosphomimic, or p85 $\alpha$ Y607F, which cannot undergo phosphorylation at this site. Although substitution of tyrosine with aspartate is not an ideal phosphotyrosine mimic, it can be used effectively in some cases and this approach has been utilized successfully, previously, for analysing p85 SH2 domain binding to phosphotyrosine sequences (29). The levels of wt p85 $\alpha$ dropped considerably after exposure to cycloheximide but were entirely retained in the presence of ACK (Figure 7B). It is also notable that the level of wt p85a in the absence of cycloheximide is higher in the presence of ACK. Y607F p85 $\alpha$ was degraded to very low levels in the presence of cycloheximide and although levels were higher in the presence of ACK, a clear reduction was observed after treatment with cycloheximide (Figure 7B). In contrast, levels of Y607D p85a decreased only slightly with cycloheximide treatment and, similar to wt $\mathrm{p} 85 \alpha$, the levels are higher in 
the presence of ACK (Figure 7B). These data indicate that ACK-dependent phosphorylation of $\mathrm{p} 85 \alpha$ Tyr607 stabilizes $\mathrm{p} 85 \alpha$ and maintains elevated protein levels.

\section{The mechanism underpinning the stabilization of p85 $\alpha$ by phosphorylation of Tyr607}

The ubiquitin-proteasome pathway regulates the stability of the p85a protein. The tumour suppressor $\mathrm{p} 42$ has been reported to promote degradation of $\mathrm{p} 85 \alpha$ by targeting its iSH2 domain (30). We have shown that the level of p85a in the cell is in part regulated by ACK and that this regulation is achieved through protection of $p 85 \alpha$ from degradation. Intriguingly, the site of ACK phosphorylation, Tyr607, is located within the iSH2 domain of p85 $\alpha$, which is flanked by two SH2 domains (Figure 1B). We hypothesized that $\mathrm{p} 85$ stabilization might be due to an intramolecular interaction between one of these $\mathrm{SH} 2$ domains and phosphoTyr607, which would result in protection of the iSH2 region from the ubiquitin-proteasome machinery.

To test this hypothesis we expressed and purified each $\mathrm{SH} 2$ domain from $\mathrm{p} 85 \alpha$ and p $85 \beta$ separately in $E$. coli. We then tested their ability to interact with peptides containing the target tyrosine and surrounding sequence from $\mathrm{p} 85 \alpha$ and $\mathrm{p} 85 \beta$, using a fluorescence polarization assay to monitor binding. The $\mathrm{nSH} 2$ domains of both $\mathrm{p} 85 \alpha$ and p $85 \beta$ interacted with a p85 $\alpha$ pY607 peptide with low micromolar affinity but bound with high affinity (low nanomolar) to a p $85 \beta$ pY607 peptide (Figure 8 and Table 1). No interaction was seen with the non-phosphorylated versions of the same sequences (Figure 8A and B) and no binding was observed between either peptide and either of the $\mathrm{cSH} 2$ domains (Figure $8 \mathrm{C}$ and $\mathrm{D}$ ). To confirm that the $\mathrm{cSH} 2$ domains were functional, binding was tested to a known target peptide from CD28 (Figure 8C and D). Binding affinities similar to those previously reported were observed, indicating that both $\mathrm{cSH} 2$ domains were capable of binding phosphopeptides (31). Thus pTyr607 supports an interaction with p $85 \alpha$ and p85 $\beta$ nSH2 domains, with higher affinity for the $\mathrm{p} 85 \beta \mathrm{pY} 607$ peptide.

We further tested the binding mode of the $\mathrm{p} 85 \mathrm{nSH} 2$ domains. An arginine residue is evolutionarily conserved amongst SH2 domains and forms a hydrogen bond with the phosphate group of the phosphotyrosine residue on binding targets (32). Mutation of this arginine to methionine in p85a completely abolishes phosphopeptide binding without disrupting the characteristic $\mathrm{SH} 2$ fold (31). Site-directed mutagenesis was used to generate SH2 mutants p85 $\alpha$ R35M and p85 $\beta$ R349M and the purified domains were analysed in binding assays. These $\mathrm{nSH} 2$ null mutations reduced binding to the phosphopeptide sequence by several orders of magnitude, indicating that the pTyr607-wildtype $\mathrm{nSH} 2$ binding mechanism is likely to be similar to other canonical p85 SH2-peptide interactions (Figure 8E and F).

As targeting of the iSH2 domain in $\mathrm{p} 85$ has been shown to induce degradation by the ubiquitin pathway (30), we speculated that phosphorylation at Tyr607 and subsequent interaction with the $\mathrm{nSH} 2$ domain would interfere with this process. HEK293T cells were transfected with FLAG-tagged p85a, Myc-tagged Ubiquitin and HA-tagged ACK and then treated with MG132, a proteasomal inhibitor, or DMSO as a control. The cell lysates were immunoprecipitated with an antibody specific for the FLAG tag and ubiquitinated p85 $\alpha$ detected with an anti-Myc antibody. Polyubiquitinated p $85 \alpha$ 
protein was detected in the MG132 treated samples as expected (Figure 8G). Coexpression of ACK however, completely abolished ubiquitination of p85 $\alpha$. Taken together these results indicate that phosphorylation of $\mathrm{p} 85 \alpha$ Tyr607 by ACK leads to an $\mathrm{nSH} 2$-phosphotyrosine interaction that blocks access to the ubiquitination machinery and thus regulates $\mathrm{p} 85 \alpha$ protein stability.

\section{ACK interacts with p85 $\alpha$ in nuclear-enriched cell fractions}

We have demonstrated that ACK phosphorylates the PI3-Kinase regulatory subunits on Tyr607 and that this promotes cell proliferation through a mechanism that does not involve an increase in lipid kinase activity. We hypothesized that phosphorylation at Tyr607 by ACK may instead promote cell proliferation by shunting PI3-Kinase or its subunits into alternative pathways independent of lipid kinase activity. We also know that phosphorylation of p85 inhibits ubiquitin-dependent degradation likely resulting in an increase in p110-free p85 subunits. The documented p110-independent functions of p85 predominate in the nucleus $(33,34)$.

To investigate whether ACK promotes cell proliferation by modulating these kinaseindependent roles of PI3-Kinase or its subunits in the nucleus, we first determined the subcellular localization of ACK and the PI3-Kinase regulatory subunits and identified their site of interaction. Whilst PI3-Kinase and ACK are primarily activated by RTKs at the plasma membrane, nuclear translocation of $\mathrm{ACK}(14,35)$ and the $\mathrm{p} 85 \alpha$ regulatory subunit $(33,36)$ have been documented. To investigate whether coexpression of ACK and p85 $\alpha$ altered the subcellular localization of either of the two proteins, HEK293T cells were transiently transfected with ACK and p85 $\alpha$ expression constructs and then separated into cytoplasmic and nuclear-enriched fractions.

ACK was found in both the cytoplasmic and nuclear-enriched fractions and this subcellular localization was not affected by co-expression with p85 $\alpha$ (Figure 9A). This suggests that ACK is able to shuttle between the nucleus and cytoplasm via a mechanism that is not regulated by its interaction with p85 $\alpha$. p $85 \alpha$ was also detected in both cellular fractions but was predominantly $(\sim 90 \%)$ in the nuclear-enriched fraction when expressed alone (Figure 9A). Co-expression with ACK increased the total amount of p85, as seen previously, and resulted in a near equal distribution of p85 between nucleus and cytoplasm.

To determine the subcellular location of ACK-p85 complexes, cellular fractions were immunoprecipitated with an anti-FLAG antibody. The interaction between $\mathrm{p} 85 \alpha$ and ACK was detected almost exclusively in nuclear-enriched fractions (Figure 9B) suggesting that phosphorylation of $\mathrm{p} 85$ by ACK occurs in the nucleus. Consistent with this, p85 pY607 was almost entirely located in the nuclear fractions (Figure S2).

To investigate whether phosphorylation of $\mathrm{p} 85 \alpha$ on Tyr607 influences its cellular location, the subcellular localisation of the p85 $\alpha$ mutants Y607D and Y607F was determined (Figure 9A). Whereas p85 $\alpha$ Y607F was equally distributed between the cytoplasmic and the nuclear-enriched fractions, a higher percentage of p85 Y607D $(\sim 70 \%)$ was nuclear suggesting that Y607 phosphorylation influences the subcellular localization of $\mathrm{p} 85$. 


\section{The pTyr607-nSH2 interaction occurs in trans and promotes formation of novel p85 dimers}

The interaction between the $\mathrm{nSH} 2$ and pTyr607 of the regulatory subunits could occur theoretically either in cis in a monomeric protein, or in trans to form a dimer. Either conformation would protect the iSH2 domain from targeting by E3 ligases. To investigate whether the pTyr607-nSH2 interaction could support dimer formation we co-expressed either FLAG-p50 $\alpha$ with V5-p85 $\beta$ or FLAG-p85 $\alpha$ with V5-p85 $\beta$. We chose to study $\mathrm{p} 85 \beta$ as peptides from this isoform had the highest affinity binding to the $\mathrm{nSH} 2$ domains tested. To distinguish between dimers formed through interactions located in the $\mathrm{N}$-terminal or $\mathrm{C}$-terminal half of the molecules we also utilized the p50 $\alpha$ isoform, which lacks the N-terminal SH3, polyproline and RhoGAP/BH regions.

Proteins were co-expressed in HEK293T cells cultured in the presence of either $10 \%$ serum or in low serum $(0.05 \%)$ followed by stimulation with EGF or insulin. p50 $\alpha$ interacted with p $85 \beta$ under all conditions, although lower levels of complex were seen in low serum. Increased p $50 \alpha-\mathrm{p} 85 \beta$ complex formation was observed in high serum or in response to EGF or insulin stimulation (Figure 10A), suggesting that dimerization is induced by growth factor signalling. Dimerization in this case must be occurring solely via C-terminal interactions. $\mathrm{p} 85 \alpha$ was also seen to interact with $\mathrm{p} 85 \beta$ (Figure 10B). Again, lower levels of complex were seen in low serum with an increase in $10 \%$ serum or following insulin or EGF stimulation The increase in this case was more modest, potentially reflecting the presence of additional N-terminally mediated dimers (Figure 10B). To investigate whether the interactions observed were mediated by the pTyr607-nSH2 interaction we determined the interaction with a p50 $\alpha$ phosphomimic mutation (Y307D, equivalent to Y607D in p85) (Figure 10C). Whereas in low serum conditions, wt p50 $\alpha$-p $85 \beta$ interaction was observed at low levels, as previously observed, a significantly increased level of p50 $\alpha$ Y307D-p85 $\beta$ dimer was seen, suggesting that phosphorylation of Tyr307 underpins this interaction.

These data demonstrate that the C-terminal regions, and specifically the pTyr607$\mathrm{nSH} 2$ interaction, support formation of a novel dimeric configuration of the regulatory subunits in response to growth signals.

Since both the ACK-p85 $\alpha$ interaction and p85 pTyr607 occur exclusively in the nucleus (Figure 9B), we investigated the subcellular location of regulatory subunit dimers. Proteins were co-expressed and the cell fractionated before coimmunoprecipitation. p50 $\alpha$-p $85 \beta$ dimers were found mainly in the nucleus, whereas p $85 \alpha-p 85 \beta$ dimers were located in both the cytoplasm and the nucleus (Figure 11). We interpret these data to indicate that $\mathrm{p} 50 \alpha-\mathrm{p} 85 \beta$ dimers, as obligate $\mathrm{C}$-terminal dimers, are mainly found in the nucleus, whereas $\mathrm{p} 85 \alpha-\mathrm{p} 85 \beta$, which are likely to be a mixture of both C-terminal and N-terminal dimers, are found in both cellular compartments. The nuclear subset is likely to comprise C-terminal dimers while the cytoplasmic will be in the $\mathrm{N}$-terminal dimer configuration. 
Regulation of the PI3-Kinase regulatory subunits by $A C K$

\section{Discussion}

We have identified the five isoforms of the class Ia PI3-Kinase regulatory subunit as novel ACK binding partners and shown that $\mathrm{p} 85 \alpha, \mathrm{p} 85 \beta, \mathrm{p} 55 \alpha$ and $\mathrm{p} 50 \alpha$ are also substrates for ACK kinase activity. These isoforms are phosphorylated by ACK at a conserved tyrosine residue (equivalent to Tyr607 in p $85 \alpha$ ) within the inter-SH2 domain of the protein, a region involved in contacting and regulating the 110 catalytic subunit of PI3-Kinase. We have shown that phosphorylation of the $p 85 \beta$ isoform at this site promotes cell proliferation in culture. This increase in cell proliferation is, unexpectedly however, not achieved through a stimulation of PI3Kinase lipid kinase activity; rather, the increase in $\mathrm{PIP}_{3}$ levels that is normally observed following EGF stimulation is suppressed. We have discovered that phosphorylation of $\mathrm{p} 85$ at Tyr607 results in stabilization of the protein by protecting it from ubiquitination and subsequent degradation by the proteosome pathway. We propose a mechanism for increased $\mathrm{p} 85$ stability mediated by an interaction involving the $\mathrm{p} 85 \mathrm{nSH} 2$ domain and the ACK phosphorylation site (Tyr607 or equivalent). This interaction likely occurs via a binding mode similar to those already described for the p85 nSH2 domain (31), as shown by abrogated binding in the R358M SH2 null mutant. It is likely that the pTyr607-nSH2 interaction masks the iSH2 region, the target site on $\mathrm{p} 85$ for the degradative machinery (30). Supporting this, we have shown that ACK protects $\mathrm{p} 85$ from polyubiquitination, with ACK expression completely abolishing ubiquitination of p85. Together, our data indicate that ACK, at least in part, regulates the cellular level of $\mathrm{p} 85$ by blocking its degradation. Indeed in their paper identifying $\mathrm{p} 42 \mathrm{Ebp} 1$ as the E3 ubiquitin ligase for $\mathrm{p} 85$, Ko et al. speculate that their results indicate a possible regulatory role for the $\mathrm{nSH} 2$ in protecting the iSH2 from the degradative machinery (30). The pTyr607-nSH2 interaction would provide a mechanism for this regulation. We have shown here that this new mechanism of protein stabilization operates in both $\mathrm{p} 85 \alpha$ and $\mathrm{p} 85 \beta$ and, we assume, will be present for the other two analogous shorter isoforms, p $55 \alpha$ and p $50 \alpha$.

We were initially surprised by our observation that active ACK, which is normally pro-proliferative, is associated with a decrease in $\mathrm{PIP}_{3}$ generation in HEK293T cells. However the adjacent site on p85, Ser608, has also been identified as a phosphorylation target, in this case for the PI3-Kinase p110 subunit. This intrinsic regulation in PI3-Kinase also decreases the activity of the enzyme, although the mechanism has not been elucidated $(37,38)$. Tyr607 itself has also been identified previously as a target site that is phosphorylated downstream of the insulin receptor, although the consequence of this for PI3-Kinase lipid kinase activity was not determined (22). The decrease in $\mathrm{PIP}_{3}$ levels following phosphorylation of Tyr607 can however potentially be explained by our observation that ACK stabilizes cellular levels of the regulatory subunits and this could manifest mechanistically via two possible routes. We have shown that ACK inhibits degradation of the $\mathrm{p} 85 \alpha$ isoform, which would lead to an excess of regulatory subunits over catalytic subunits. p110free p85 exists(24) and can form homodimers (39). The formation of both $\mathrm{p} 110$-free monomeric $\mathrm{p} 85$ and dimeric $\mathrm{p} 85$ would be promoted by elevated levels of $\mathrm{p} 85$. p110free $\mathrm{p} 85$ is thought to compete with PI3-Kinase heterodimers for binding to pYXXM motifs on activated RTKs. This dampens the activation of PI3-Kinase in response to growth factors and could explain the reduced levels of $\mathrm{PIP}_{3}$ we observed following EGF stimulation of cells overexpressing ACK. More recent work has shown that p $85 \alpha$ homodimers can also bind to unphosphorylated PTEN at the plasma membrane 
and stimulate its catalytic activity (40). It is therefore also possible that the ACKdriven increase in $\mathrm{p} 110$-free $\mathrm{p} 85 \alpha$, leads to an increase in $\mathrm{p} 85$ homodimers, which promotes PTEN activity, leading to decreased $\mathrm{PIP}_{3}$ levels.

It is also apparent from our work that the interaction between pTyr607 and the nSH2 domain in the regulatory subunits underpins a novel mechanism of dimerization for these proteins. Using the wealth of structural data available for $\mathrm{p} 85 \alpha$, we constructed a model of how these dimers could form (Figure 12). Structural data is not available currently for p85 $\alpha$ residues 599-611, so p $85 \alpha$ residues 604-611 were modelled into the structure based on the known binding site of a phosphopeptide on the $\mathrm{p} 85 \alpha \mathrm{nSH} 2$ domain. Using the available structural data, an intramolecular monomeric interaction between the $\mathrm{nSH} 2$ and pTyr607 is highly unlikely to occur due to steric clashes, suggesting that the nSH2-pTYr607 interaction results in dimer formation. Figure 12 shows the most likely arrangement of a p $85 \alpha-p 85 \alpha$ homodimer (upper panel) and a p $85 \alpha-p 50 \alpha$ heterodimer (middle panel). Details of the nSH2-pTyr607 interaction in the context of the dimer are shown in Figure 12 (lower panel).

The $\mathrm{p} 85$ subunits are well documented to homodimerize via a trans interaction between the N-terminal SH3 domain and its juxtaposed proline rich motif (PR1) (41). The RhoGAP (BH) domain has also been shown to mediate homodimerization (41). Both of these interactions are relatively weak and it has been proposed that multiple sites of interaction may contribute to producing a stable $\mathrm{p} 85$ homodimer, allowing multiple levels of co-ordinated regulation that are common in signalling systems (40, 41). The pTyr607-nSH2 interaction we have identified provides a novel mechanism to mediate dimerization of the PI3K regulatory subunits via the $\mathrm{C}$-terminal regions of the proteins (Figure 12). This interaction is high affinity and therefore sufficient to support dimerization in the absence of other contributing interactions. Unlike the SH3-PR1 and BH-mediated dimerization modes, both of which involve N-terminal regions of the protein, the pTyr607-nSH2 interaction also exists in the shorter isoform $\mathrm{p} 50 \alpha$ and likely in $\mathrm{p} 55 \alpha$ (Figure 12). Our data demonstrate that heterodimerization is supported between $\mathrm{p} 85 \beta$ and both $\mathrm{p} 50 \alpha$ and $\mathrm{p} 85 \alpha$, but could potentially occur between any of the four phosphorylated regulatory subunit isoforms, as the $\mathrm{nSH} 2$ domains from $\mathrm{p} 85 \alpha$ and $\mathrm{p} 85 \beta$ bind to phosphopeptides representing sequences from both $\mathrm{p} 85 \alpha$ and $\mathrm{p} 85 \beta$. The $\mathrm{nSH} 2$ and peptide sequences for $\mathrm{p} 85 \alpha$ are identical to its splice variants $\mathrm{p} 55 \alpha$ and $\mathrm{p} 50 \alpha$, implying that any combination of isoforms could potentially form heterodimers. Our affinity data indicate preference for binding to the $\mathrm{p} 85 \beta$ peptide in both cases, which is not surprising as the $\mathrm{p} 85 \beta$ peptide conforms well to the consensus sequence for a p85 SH2 domain binding target. This suggests that $\alpha$ isoforms should preferentially heterodimerize with $p 85 \beta$, while $p 85 \beta$ would preferentially form homodimers. The functional ramifications of this remain to be investigated. Importantly, this new mechanism of dimerization is also regulated by phosphorylation, only being present in conditions where ACK is active. This might explain why it has not been identified in previous studies, especially those using recombinant proteins.

Dimerization of the regulatory subunits also has implications for the binding of other potential cellular ligands. Different p85 dimers would retain the ability to bind to a unique subset of cellular partners defined by the regions not involved in dimerization. p85 dimers mediated by N-terminal interactions could retain the ability to interact with, for example, the p110 catalytic subunit. Dimerization mediated by N-terminal 
regions also seems to be a pre-requisite for $\mathrm{p} 85$ to bind to PTEN and enhance its phosphatase activity, so negatively regulating $\mathrm{PIP}_{3}$ production in cells (40). Importantly a p85 dimer where the $\mathrm{nSH} 2$ domain is bound to pTyr607 in trans is unlikely to retain the ability to bind to the p110 catalytic subunits: multiple contacts to the p110 subunit occur within the $\mathrm{nSH} 2$ and iSH2 regions of the regulatory subunits. Analysis of the available structural data suggests that, if the $\mathrm{nSH} 2$ is bound to a phosphopeptide located in the iSH2, clashes would exist with the p110 catalytic subunit, implying that an pTyr607-nSH2 interaction would alter the p85-p110 heterodimer (Figure 12). As p85-free p110 is unstable and degraded quickly, this could contribute to the decrease in $\mathrm{PIP}_{3}$ levels we observe.

A p85 homo or heterodimer utilizing the $\mathrm{nSH} 2$ in a classical phospho-tyrosine interaction will also be modulated in its ability to bind RTKs and therefore potentially in competing with the PI3-Kinase heterodimer for activation. On the other hand, the cSH2 would still be available to interact with RTKs (Figure 12). p85 interactions with RTKs are complex, with the $\mathrm{nSH} 2$ and $\mathrm{cSH} 2$ having different affinities for different pTyr motifs $(31,42,43)$. The availability of only the cSH2 might be expected to have variable effects on the ability of a pTyr607-nSH2 p85 dimer to bind to RTKs. However the $\mathrm{cSH} 2$ domain is often seen to have higher affinity for receptor sequences than the $\mathrm{nSH} 2(31,42,43)$. Thus competition could be the mechanism underpinning the decrease in $\mathrm{PIP}_{3}$ we observe. This newly identified pTyr607-nSH2 dimer could also retain the ability to bind to and activate PTEN, likewise leading to decreased levels of $\mathrm{PIP}_{3}$. Further work will be required to determine whether pTyr607 p85 retains the ability to form dimers that can interact with RTKs and/or PTEN.

The dimers we describe here would, in contrast to those previously reported, leave the $\mathrm{N}$-terminal regions of $\mathrm{p} 85 \alpha / \beta$ available for further interactions (Figure 12).

Interestingly the only potential catalytic domain of $\mathrm{p} 85 \alpha / \beta$, the RhoGAP domain (BH domain) resides in the $\mathrm{N}$-terminal regions of the proteins and the catalytic cleft on this domain is available to engage substrates (Figure 12). The proline-rich regions and RhoGAP/BH domain of $\mathrm{p} 85$ have been shown to regulate the actin cytoskeleton, with their deletion inhibiting lamellipodia formation (44). Cdc42-WASP controlled formation of filopodia is also regulated by p85 (45). Although the p85 RhoGAP domain binds to both Rac1 and Cdc42, GAP activity towards either small $\mathrm{G}$ protein, if it exists at all, is very low (46). Indeed, p85 appears to increase signalling from these small GTPases, in opposition to the traditional role of a GAP domain. The RhoGAP/BH domain is also thought to be a GAP for Rab proteins, including Rab5, albeit with equally low activity, and to therefore play a role in receptor endocytosis $(46,47)$. The SH3 domain of the $\mathrm{p} 85$ subunits interacts with many target proteins, which, in different contexts, functionally confer mechanisms to activate PI3-Kinase independent of the SH2 domains, inhibit PI3-kinase, regulate endocytosis or regulate the p85 protein itself (48). All of these interactions would be available in a pTyr607$\mathrm{nSH} 2$ driven dimer and could be functionally altered in this new dimeric configuration (Figure 12).

A growing roster of PI3-Kinase independent functions for the p85 regulatory subunits exists. p85 plays roles in various stress response pathways, regulating p53, XBP-1 and $\operatorname{BRD} 7(33,34,36,49,50)$. Intriguingly the $\mathrm{p} 85$ regulatory subunits are also known to act independently of PI3-Kinase to potentiate c-Jun N-terminal kinase (JNK)mediated insulin resistance. In this instance $\mathrm{p} 85$ acts as a negative regulator of 
insulin/PI3-Kinase signalling by increasing JNK activation. The activation of JNK in response to insulin is mediated by a Cdc $42 / \mathrm{MKK} 4$ pathway and $\mathrm{p} 85$ seems to act by increasing levels of active Cdc42 (51). Our data add another layer of regulation to this network of feedback loops. As well as activating MKK4, Cdc42 will activate ACK, which in turn will increase p85 levels, potentially reinforcing JNK-mediated insulin resistance. This suggests a potential role for ACK in type 2 diabetes. It remains to be determined which other interactions and cellular processes a pTyr607-nSH2 p85 dimer can support and therefore what the overall impact of Cdc42/ACK signalling on p85 function will be.

ACK has been shown previously to shuttle between the cytoplasm and the nucleus in a Cdc42 dependent manner (35). Once in the nucleus it has a number of important roles in regulating transcription e.g. by influencing the androgen receptor and FoxO transcription factors $(13,52)$. However unlike BRD7, which binds to the iSH2 region and translocates p85 to the nucleus (36), our data support a model where ACK and p85 access the nucleus independently and only interact once in this compartment. Subsequently the dimers that form also appear to exist predominantly in the nucleus, suggesting a novel nuclear function for the regulatory subunits based on the new dimer configuration described here. Many of the roles of $\mathrm{p} 85$ in the nucleus revolve around regulation of transcription of genes that control cell proliferation or senescence, alongside protection of the cell from different forms of stress. We therefore suggest that ACK promotes cell proliferation, at least in part, through phosphorylation of free $\mathrm{p} 85$ in the nucleus. This results in a parallel increase in nuclear levels of p85 and subsequent formation of the pTyr607-nSH2 dimer, which may play a role in regulating gene transcription.

The work presented here, along with a growing body of literature describing the cellular effects of ACK, indicates that ACK regulates PI3-Kinase signalling at multiple nodes, suggesting that signalling through PI3-kinase is extremely important to the physiological functions of ACK. Our initial discovery that the p85 regulatory subunits were new targets for ACK led us to assume that ACK would act to relieve the inhibitory effects of the regulatory subunits, leading to activation of PI3-Kinase, based on the pro-proliferative activity of ACK. The reduction in $\mathrm{PIP}_{3}$ levels we observe are hard to reconcile with the growth promoting activity of ACK. Our initial hypothesis was however always somewhat perplexing, as ACK can interact with and phosphorylate Akt directly, providing a potential membrane localization signal to contribute to the activation of Akt (18). Phosphorylation of Tyr176 also appears to drive Akt to the nucleus where it can phosphorylate the FoxO transcription factors, leading to their relocation to the cytoplasm and stimulation of the cell cycle. The reason why two pathways to Akt activation, i.e. RTKs/PI3-Kinase or ACK, are employed in cells seemed elusive(18). However our discovery that the ACK expression results in a decrease in $\mathrm{PIP}_{3}$ levels may go some way to explaining the necessity for direct Akt activation by ACK, independent of PI3-Kinase.

Our data implies that the effects that ACK is able to exert via the free p85 pool must be paramount to its pro-proliferative role, such that it also has the ability to maintain downstream activation of the canonical 'PI3-Kinase' pro-proliferative pathways (via Akt), while directing $\mathrm{p} 85$ to perform other vital roles in the nucleus. Via this mechanism, ACK would be able to shape PI3-Kinase signalling responses, promoting the activity of pathways downstream of Akt, whilst suppressing signalling in other 
PI3-Kinase effector pathways and stimulating free dimeric p85 functions (Figure 13). It remains to be investigated whether ACK can directly activate further pathways conventionally downstream of PI3-Kinase/PIP 3 .

Growing evidence in the literature demonstrates that the relative amounts of $\mathrm{p} 85 / \mathrm{p} 110$ heterodimer and p110-free p85 homodimer are critical in regulating the PI3-Kinase pathway and a number of other pathways regulated by $\mathrm{p} 85$ homodimers. We demonstrate here that ACK perturbs this gatekeeper equilibrium and suggest that this feature of ACK contributes to the oncogenic potential of this kinase. Most importantly we have identified a new form of PI3-Kinase regulatory subunit dimers, which form exclusively in the nucleus and must undertake pro-proliferative roles. 
Regulation of the PI3-Kinase regulatory subunits by ACK

\begin{abstract}
Abbreviations
BH, Bcr homology; CRIB, Cdc42/Rac interactive binding; EBD, EGFR binding domain; EGF, epidermal growth factor; GAP, GTPase activating protein, NES, Nuclear export signal; $\mathrm{PIP}_{2}$, phosphatidylinositol 4,5-bisphosphate; $\mathrm{PIP}_{3}$, phosphatidylinositol $(3,4,5)$-trisphosphate; RTK, receptor tyrosine kinase; SAM, sterile alpha motif; SH2, Src homology 2 domain; SH3, Src homology 3 domain; UBA, ubiquitin association.
\end{abstract}

\title{
Author contributions
}

H.R.M. and D.O. conceptualized the project. N.S.C., M.F., J. J. V-G., C.M.S., T.D.L., J.I.W., J.C., K.K., Q.Z., M.J.O.W., M.J.B.B., C.C., H.R.M and D.O. designed and performed the experiments. N.S.C., M.F., C.M.S., J.I.W., J.C., Q.Z., M.J.O.W., M.J.B.B., C.C., H.R.M and D.O. interpreted and analysed the data. N.S.C., M.F., H.R.M and D.O. wrote the manuscript with contributions from all other authors.

\section{Funding}

This research was supported by: BBSRC DTG/A studentships (BB/F017464/1 and BB/A517685/1) to NSC and JV-G; an MRC iCASE (MR/N018354/1) to DO and CC; a Churchill Scholarship (awarded by the Winston Churchill Foundation of the United States) to CS; a CR-UK (C4750/A19013) programme grant to TDL; a National Overseas Scholarship, Government of India and a Cambridge Commonwealth Scholarship to KK; a BBSRC research grant (BB/P013384/1) to MJOW and a CR-UK project grant (C11309/A5148) to DO and HRM. Thanks also to the Amgen Foundation for the financial support provided through the Amgen Scholars Programme to JC.

\section{Acknowledgements}

We are very grateful to Dr Marc de la Roche and Dr Catherine Lindon for helpful discussions. We are also indebted to Dr Elizabeth Smethurst for expert assistance in quantifying $\mathrm{PIP}_{3}$ levels. Phosphorylation site mapping was carried out by Dr. Mike Deery, Cambridge Centre for Proteomics, University of Cambridge.

\section{Competing interest}

The authors declare that they have no conflicts of interest with the contents of this article. 


\section{References}

1. Arias-Romero LE, Chernoff J. Targeting Cdc42 in cancer. Expert Opin Ther Targets. 2013;17(11):1263-73.

2. Stengel KR, Zheng Y. Essential Role of Cdc42 in Ras-Induced Transformation Revealed by Gene Targeting. PLoS One. 2012;7(6):e37317.

3. Fritz G, Brachetti C, Bahlmann F, Schmidt M, Kaina B. Rho GTPases in human breast tumours: expression and mutation analyses and correlation with clinical parameters. Br J Cancer. 2002;87(6):635-44.

4. Tucci MG, Lucarini G, Brancorsini D, Zizzi A, Pugnaloni A, Giacchetti A, et al. Involvement of E-cadherin, beta-catenin, Cdc42 and CXCR4 in the progression and prognosis of cutaneous melanoma. Br J Dermatol. 2007;157(6):1212-6.

5. Liu Y, Wang Y, Zhang Y, Miao Y, Zhao Y, Zhang PX, et al. Abnormal expression of p120-catenin, E-cadherin, and small GTPases is significantly associated with malignant phenotype of human lung cancer. Lung Cancer. 2009;63(3):375-82.

6. Lin R, Cerione RA, Manor D. Specific contributions of the small GTPases Rho, Rac, and Cdc42 to Dbl transformation. J Biol Chem. 1999;274(33):23633-41.

7. Hamann MJ, Lubking CM, Luchini DN, Billadeau DD. Asef2 functions as a Cdc42 exchange factor and is stimulated by the release of an autoinhibitory module from a concealed C-terminal activation element. Mol Cell Biol. 2007;27(4):1380-93.

8. Durkin ME, Yuan BZ, Zhou X, Zimonjic DB, Lowy DR, Thorgeirsson SS, et al. DLC-1: a Rho GTPase-activating protein and tumour suppressor. J Cell Mol Med. 2007;11(5):1185-207.

9. Manser E, Leung T, Salihuddin H, Tan L, Lim L. A Nonreceptor Tyrosine Kinase That Inhibits the GTPase Activity of p21(Cdc42). Nature. 1993;363(6427):364-7. 10. Greenman C, Stephens P, Smith R, Dalgliesh GL, Hunter C, Bignell G, et al. Patterns of somatic mutation in human cancer genomes. Nature. 2007;446(7132):1538 .

11. van der Horst EH, Degenhardt YY, Strelow A, Slavin A, Chinn L, Orf J, et al. Metastatic properties and genomic amplification of the tyrosine kinase gene ACK1. Proc Natl Acad Sci U S A. 2005;102(44):15901-6.

12. Mahajan NP, Whang YE, Mohler JL, Earp HS. Activated tyrosine kinase Ack1 promotes prostate tumorigenesis: Role of Ack1 in polyubiquitination of tumor suppressor Wwox. Cancer Res. 2005;65(22):10514-23.

13. Mahajan K, Malla P, Lawrence HR, Chen ZH, Kumar-Sinha C, Malik R, et al. ACK1/TNK2 Regulates Histone H4 Tyr88-phosphorylation and AR Gene Expression in Castration-Resistant Prostate Cancer. Cancer Cell. 2017;31(6):790-803.

14. Mahajan NP, Liu Y, Majumder S, Warren MR, Parker CE, Mohler JL, et al. Activated Cdc42-associated kinase Ack1 promotes prostate cancer progression via androgen receptor tyrosine phosphorylation. Proc Natl Acad Sci U S A. 2007;104(20):8438-43.

15. Yap TA, Bjerke L, Clarke PA, Workman P. Drugging PI3K in cancer: refining targets and therapeutic strategies. Curr Opin Pharmacol. 2015;23:98-107.

16. Thorpe LM, Yuzugullu H, Zhao JJ. PI3K in cancer: divergent roles of isoforms, modes of activation and therapeutic targeting. Nature Reviews Cancer. 2015;15(1):724. 
17. Cheung LW, Yu S, Zhang D, Li J, Ng PK, Panupinthu N, et al. Naturally occurring neomorphic PIK3R1 mutations activate the MAPK pathway, dictating therapeutic response to MAPK pathway inhibitors. Cancer Cell. 2014;26(4):479-94. 18. Mahajan K, Coppola D, Challa S, Fang B, Chen YA, Zhu WW, et al. Ack1 Mediated AKT/PKB Tyrosine 176 Phosphorylation Regulates Its Activation. PLoS One. 2010;5(3): e9646.

19. Clark J, Anderson KE, Juvin V, Smith TS, Karpe F, Wakelam MJO, et al. Quantification of PtdInsP(3) molecular species in cells and tissues by mass spectrometry. Nature Methods. 2011;8(3):267-U120.

20. Yokoyama N, Miller WT. Purification and Enzyme Activity of ACK1. 2006;406:250-60.

21. Galisteo ML, Yang Y, Urena J, Schlessinger J. Activation of the nonreceptor protein tyrosine kinase Ack by multiple extracellular stimuli. Proc Natl Acad Sci U S A. 2006;103(26):9796-801.

22. Hayashi H, Nishioka Y, Kamohara S, Kanai F, Ishii K, Fukui Y, et al. The alphatype $85-\mathrm{kDa}$ subunit of phosphatidylinositol 3-kinase is phosphorylated at tyrosine368 , tyrosine-580, and tyrosine-607 by the insulin-receptor. J Biol Chem. 1993;268(10):7107-17.

23. Burke JE, Perisic O, Masson GR, Vadas O, Williams RL. Oncogenic mutations mimic and enhance dynamic events in the natural activation of phosphoinositide 3kinase p110 alpha (PIK3CA). Proc Natl Acad Sci U S A. 2012;109(38):15259-64. 24. Ueki K, Fruman DA, Brachmann SM, Tseng YH, Cantley LC, Kahn CR. Molecular Balance between the Regulatory and Catalytic Subunits of Phosphoinositide 3-Kinase Regulates Cell Signaling and Survival. Mol Cell Biol. 2002;22(3):965-77.

25. Bandyopadhyay GK, Yu JG, Ofrecio J, Olefsky JM. Increased p85/55/50 expression and decreased phosphotidylinositol 3-kinase activity in insulin-resistant human skeletal muscle. Diabetes. 2005;54(8):2351-9.

26. Mahajan K, Coppola D, Rawal B, Chen YA, Lawrence HR, Engelman RW, et al. Ack1-mediated Androgen Receptor Phosphorylation Modulates Radiation Resistance in Castration-resistant Prostate Cancer. J Biol Chem. 2012;287(26):22112-22.

27. Terauchi Y, Tsuji Y, Satoh S, Minoura H, Murakami K, Okuno A, et al. Increased insulin sensitivity and hypoglycaemia in mice lacking the p85 alpha subunit of phosphoinositide 3-kinase. Nat Genet. 1999;21(2):230-5.

28. Barbour LA, Shao JH, Qiao LP, Leitner W, Anderson M, Friedman JE, et al. Human placental growth hormone increases expression of the p 85 regulatory unit of phosphatidylinositol 3-kinase and triggers severe insulin resistance in skeletal muscle. Endocrinology. 2004;145(3):1144-50.

29. Cuevas BD, Lu Y, Mao M, Zhang J, LaPushin R, Siminovitch K, et al. Tyrosine phosphorylation of $\mathrm{p} 85$ relieves its inhibitory activity on phosphatidylinositol 3kinase. J Biol Chem. 2001;276(29):27455-61.

30. Ko HR, Kim CK, Lee SB, Song J, Lee KH, Kim KK, et al. P42 Ebp1 regulates the proteasomal degradation of the $\mathrm{p} 85$ regulatory subunit of $\mathrm{PI} 3 \mathrm{~K}$ by recruiting a chaperone-E3 ligase complex HSP70/CHIP. Cell Death Dis. 2014;5:e1131.

31. Inaba S, Numoto N, Ogawa S, Morii H, Ikura T, Abe R, et al. Crystal Structures and Thermodynamic Analysis Reveal Distinct Mechanisms of CD28 Phosphopeptide Binding to the Src Homology 2 (SH2) Domains of Three Adaptor Proteins. J Biol Chem. 2017;292(3):1052-60. 
32. Siegal G, Davis B, Kristensen SM, Sankar A, Linacre J, Stein RC, et al. Solution structure of the C-terminal SH2 domain of the p85 alpha regulatory subunit of phosphoinositide 3-kinase. J Mol Biol. 1998;276(2):461-78.

33. Park SW, Zhou Y, Lee J, Lu A, Sun C, Chung J, et al. The regulatory subunits of PI3K, p85 alpha and p85 beta, interact with XBP-1 and increase its nuclear translocation. Nat Med. 2010;16(4):429-U111.

34. Song L, Gao M, Dong W, Hu M, Li J, Shi X, et al. p85alpha mediates p53 K370 acetylation by $\mathrm{p} 300$ and regulates its promoter-specific transactivity in the cellular UVB response. Oncogene. 2011;30(11):1360-71.

35. Ahmed I, Calle Y, Sayed MA, Kamal JM, Rengaswamy P, Manser E, et al. Cdc42-dependent nuclear translocation of non-receptor tyrosine kinase, ACK. Biochem Biophys Res Commun. 2004;314(2):571-9.

36. Chiu Y-H, Lee JY, Cantley LC. BRD7, a Tumor Suppressor, Interacts with p85 alpha and Regulates PI3K Activity. Mol Cell. 2014;54(1):193-202.

37. Dhand R, Hara K, Hiles I, Bax B, Gout I, Panayotou G, et al. PI3-kinase structural and functional-analysis of intersubunit interactions. EMBO J. 1994;13(3):511-21.

38. Foukas LC, Beeton CA, Jensen J, Phillips WA, Shepherd PR. Regulation of phosphoinositide 3-kinase by its intrinsic serine kinase activity in vivo. Mol Cell Biol. 2004;24(3):966-75.

39. LoPiccolo J, Kim SJ, Shi Y, Wu B, Wu HY, Chait BT, et al. Assembly and Molecular Architecture of the Phosphoinositide 3-Kinase p85 alpha Homodimer. J Biol Chem. 2015;290(51):30390-405.

40. Cheung LWT, Walkiewicz KW, Besong TMD, Guo H, Hawke DH, Arold ST, et al. Regulation of the PI3K pathway through a 885 alpha monomer-homodimer equilibrium. Elife. 2015;4:e06866.

41. Harpur AG, Layton MJ, Das P, Bottomley MJ, Panayotou G, Driscoll PC, et al. Intermolecular interactions of the $\mathrm{p} 85$ alpha regulatory subunit of phosphatidylinositol 3-kinase. J Biol Chem. 1999;274(18):12323-32.

42. Panayotou G, Gish G, End P, Troung O, Gout I, Dhand R, et al. Interactions between $\mathrm{SH} 2$ domains and tyrosine-phosphorylated platelet-derived growth-factor beta-receptor sequences - analysis of kinetic-parameters by a novel biosensors-based approach. Mol Cell Biol. 1993;13(6):3567-76.

43. Ponzetto C, Bardelli A, Maina F, Longati P, Panayotou G, Dhand R, et al. A novel recognition motif for phosphatidylinositol 3-kinase binding mediates its association with the hepatocyte growth-factor scatter factor-receptor. Mol Cell Biol.

1993;13(8):4600-8.

44. Hill KM, Huang Y, Yip SC, Yu J, Segall JE, Backer JM. N-terminal domains of the class ia phosphoinositide 3-kinase regulatory subunit play a role in cytoskeletal but not mitogenic signaling. J Biol Chem. 2001;276(19):16374-8.

45. Jimenez C, Portela RA, Mellado M, Rodriguez-Frade JM, Collard J, Serrano A, et al. Role of the PI3K regulatory subunit in the control of actin organization and cell migration. J Cell Biol. 2000;151(2):249-61.

46. Chamberlain MD, Berry TR, Pastor MC, Anderson DH. The p85alpha subunit of phosphatidylinositol 3'-kinase binds to and stimulates the GTPase activity of Rab proteins. J Biol Chem. 2004;279(47):48607-14.

47. Chamberlain MD, Oberg JC, Furber LA, Poland SF, Hawrysh AD, Knafelc SM, et al. Deregulation of Rab5 and Rab4 proteins in p85R274A-expressing cells alters PDGFR trafficking. Cell Signal. 2010;22(10):1562-75. 
48. Mellor P, Furber LA, Nyarko JN, Anderson DH. Multiple roles for the p85alpha isoform in the regulation and function of PI3K signalling and receptor trafficking. Biochem J. 2012;441(1):23-37.

49. Yin YX, Terauchi Y, Solomon GG, Aizawa S, Rangarajan PN, Yazaki Y, et al. Involvement of p85 in p53-dependent apoptotic response to oxidative stress. Nature. 1998;391(6668):707-10.

50. Park SW, Herrema H, Salazar M, Cakir I, Cabi S, Sahin FB, et al. BRD7 Regulates XBP1s' Activity and Glucose Homeostasis through Its Interaction with the Regulatory Subunits of PI3K. Cell Metab. 2014;20(1):73-84.

51. Taniguchi CM, Aleman JO, Ueki K, Luo J, Asano T, Kaneto H, et al. The p85alpha regulatory subunit of phosphoinositide 3-kinase potentiates c-Jun Nterminal kinase-mediated insulin resistance. Mol Cell Biol. 2007;27(8):2830-40. 52. Mahajan K, Mahajan NP. Shepherding AKT and Androgen Receptor by Ack1 Tyrosine Kinase. J Cell Physiol. 2010;224(2):327-33. 
Table 1: Equilibrium binding constants for p85 SH2 domains and phosphorylated peptides

\begin{tabular}{|c|c|c|c|}
\hline \multicolumn{4}{|c|}{$K_{\mathrm{d}}(\mathrm{nM})^{\mathrm{a}}$} \\
\hline $\mathrm{p} 85 \alpha \mathrm{nSH} 2$ & $\begin{array}{c}\text { pYSLV }(\alpha \\
\text { peptide })\end{array}$ & $\begin{array}{c}\text { pYSLV }(\beta \\
\text { peptide })\end{array}$ & $\begin{array}{c}\text { pCD28 } \\
\text { peptide }\end{array}$ \\
\hline $\mathrm{p} 85 \beta \mathrm{nSH} 2$ & $2400 \pm 315$ & $82 \pm 16$ & - \\
\hline $\mathrm{p} 85 \alpha \mathrm{cSH} 2$ & $9000 \pm 282$ & $52 \pm 8$ & - \\
\hline $\mathrm{p} 85 \beta \mathrm{cSH} 2$ & 84000 & $656 \pm 424$ & $43 \pm 10$ \\
\hline $\mathrm{p} 85 \alpha \mathrm{nSH} 2 \mathrm{R} 358 \mathrm{M}$ & $\mathrm{ND}$ & $\mathrm{ND}$ & $100 \pm 27$ \\
\hline $\mathrm{p} 85 \beta \mathrm{nSH} 2 \mathrm{R} 349 \mathrm{M}$ & $\mathrm{ND}$ & $2900 \pm 1600$ & - \\
\hline
\end{tabular}

${ }^{\text {a }}$ Standard error where $\mathrm{n}=3$

${ }^{\mathrm{b}} \mathrm{ND}$ (no binding) denotes data that could not be fitted to the binding isotherm 
Regulation of the PI3-Kinase regulatory subunits by ACK

\section{Figure Legends}

Figure 1: Domain architecture of $\mathrm{ACK}$ and the $\mathrm{p85}$ regulatory subunit with a summary of the yeast two hybrid results. (A) Domain architecture of ACK. SAM: sterile alpha motif domain, NES: nuclear export signal, SH3: Src homology-3 domain, CRIB: Cdc42/Rac-interactive binding motif, Clath: clathrin binding region, EBD: EGFR binding domain, UBA: ubiquitin association region. The region in the Nterminus of ACK used for the yeast-2-hybrid screen is indicated by the red box. (B) Domain architecture of class Ia PI3-Kinase regulatory subunits. SH3: Src homology-3 domain, P: proline-rich sequences, RhoGAP: region with sequence homology to Rho family GTPase-activating domains, SH2: Src homology-2 domain, nSH2: N-terminal $\mathrm{SH} 2$ domain, cSH2: C-terminal SH2 domain, iSH2: inter-SH2 region. Regions involved in interactions with ACK, as identified by the yeast-2-hybrid screen, are indicated by red boxes. The ACK phosphorylation site in $\mathrm{p} 85 \alpha$ and the equivalent tyrosine residues in $\mathrm{p} 50 \alpha, \mathrm{p} 55 \alpha, \mathrm{p} 85 \beta$ and $\mathrm{p} 55 \gamma$ are shown in bold.

Figure 2: Interaction of ACK with p85 $\alpha, \mathrm{p55} \alpha, \mathrm{p50} \alpha, \mathrm{p85} \beta$ and $\mathrm{p55} \gamma$ in HEK293 cells. HA-ACK and HA-dACK (a kinase dead mutant, K158R) were expressed alone and with the FLAG tagged PI3-Kinase regulatory subunit isoforms $\mathrm{p} 85 \alpha(\mathrm{A}), \mathrm{p} 55 \alpha(\mathrm{B}), \mathrm{p} 50 \alpha(\mathrm{C}), \mathrm{p} 85 \beta$ (D) and p55 $\gamma(\mathrm{E})$. Expression of the recombinant proteins in whole cell lysate (WCL) is shown in the bottom panels. PI3-Kinase regulatory subunit isoforms were immunoprecipitated from cell lysates using an antiFLAG antibody and the co-immunoprecipitation of ACK and/or dACK was assessed using an anti-HA antibody (top panels). Results are representative of at least three independent experiments.

\section{Figure 3: Phosphorylation of full-length FLAG-tagged regulatory subunit} isoforms by full-length HA-ACK in HEK293T cells. (A-E) HEK293T cells were harvested 40 hours after transfection with FLAG-tagged regulatory subunit isoforms in the presence and absence of HA-ACK/HA-dACK. Phosphorylation of FLAGtagged regulatory subunit isoforms was assessed by western blotting of cell lysates using an antibody raised against the p85 sequence (D-Q-Y $\left.{ }_{(p)}-\mathrm{S}-\mathrm{L}\right)$ and/or a pan antipTyr antibody. The red box in (E) denotes the region where a signal for $\mathrm{pTyr}$ p55 $\gamma$ would be expected. Results are representative of at least three independent experiments. (F) Amino acid sequence alignment surrounding Tyr607 or equivalent (red) in all p85 isoforms. Sequence recognized by the anti-p85 (pTyr607) antibody is shown in blue.

Figure 4: Phosphorylation of the PI3-Kinase regulatory subunits in vitro. Fulllength GST-tagged regulatory subunits or GST control were incubated at $30{ }^{\circ} \mathrm{C}$ for 30 minutes with $\mathrm{His}_{6}$-ACK (110-489) or GST-ACK (1-489). Reactions were analysed by SDS-PAGE and Coomassie staining (left panels) and western blotting using anti-p85 (pTyr607) and anti-ACK (pTyr284) antibodies (right panels). Results are representative of at least three independent experiments. (A) p85 $\alpha$ is phosphorylated on Tyr607 by purified His 6 -ACK110-189, (B) p55 $\alpha$ is phosphorylated on Tyr337, (C) p50 $\alpha$ is phosphorylated on Tyr307 and (D) p $85 \beta$ is phosphorylated on Tyr599 by purified GST-ACK (1-489) in vitro.

Figure 5: Proliferation of HEK293T cells expressing ACK and p85 $\beta$ variants. (A) Proliferation of HEK293T cells stably expressing wt ACK and caACK. HEK293T 
cells containing empty vector or stably expressing HA-wt ACK or caACK were seeded at a density of $3 \times 10^{4}$ cells per well. Cells were plated in replicates of 5 and live cell counts were obtained at the times indicated. Data from three independent experiments is shown. Error bars represent standard deviation. Inset shows the relative levels of ACK in the wt and caACK cell lines by western blot analysis. Data from the $96 \mathrm{~h}$ time point is also shown in a bar chart on the right hand side. Group significance testing was performed by T-test: *, p $<0.05 ; * *, p<0.01$.

B) Proliferation of HEK293T cells stably expressing wt $\mathrm{p} 85 \beta$ and Y599F p85 $\beta$. HEK293T cells stably expressing inducible FLAG-tagged wt $p 85 \beta$ or $p 85 \beta$ Y $599 \mathrm{~F}$ were seeded at a density of $3 \times 10^{4}$ cells per well and incubated at $37^{\circ} \mathrm{C}$ for 16 hours. Cells were then treated with $1 \mu \mathrm{g} / \mathrm{mL}$ doxycycline and incubated at $37^{\circ} \mathrm{C}$ for the times indicated before live cell counts were taken. Certain cell lines were treated with the ACK inhibitor AIM-100 $(8 \mu \mathrm{M})$ as indicated. Data from three independent experiments is shown. Error bars represent standard deviation. Inset shows the relative levels of p85 in the wt and Y599F cell lines by western blot analysis. Data from the $96 \mathrm{~h}$ time point is also shown in a bar chart on the right hand side. Group significance testing was performed by T-test: *, p $<0.05 ; * *, p<0.01, * * *, p<0.001$.

Figure 6: Effect of exogenous wtACK and caACK expression on $\mathrm{PIP}_{3}$ levels in serum-starved HEK293T cells. Cells were transfected with GFP, HA-wtACK or HA-caACK for 24 hours. Cells were then grown in 0\% FBS DMEM for 16 hours before stimulation with EGF. (A) Whole cell lysates from one experimental replicate were normalised by Bradford assay and $80 \mu \mathrm{g}$ of each lysate was analysed by Western blotting using an anti-HA antibody to confirm similar levels of expression of HAACK and HA-caACK. (B) PIP $_{3}$ and PIP $_{2}$ were extracted and quantified using HPLCMS. $\mathrm{PIP}_{3}$ levels are expressed as a ratio of the mean total cellular $\mathrm{PIP}_{3}$ to mean total cellular $\mathrm{PIP}_{2}$ (error bars show the standard deviation from $\mathrm{n}=3$ technical repeats). Responses were normalized for cell input using a 16:0/17:0-PIP 3 internal standard. Data is representative of trends observed in three independent experiments.

Figure 7: Stabilization of p85a by ACK in vivo. (A) HEK293T cells were transfected with either HA-caACK or HA-GFP and then treated with cycloheximide $(+)$ or DMSO (-). Cell lysates were immunoprecipitated using an anti-p85 $\alpha$ antibody. Western blotting with an anti-ACK antibody was used to assess the expression of HAcaACK in whole cell lysates (top panel) and an anti-p85 $\alpha$ antibody was used to assess the amount of immunoprecipitated endogenous p85 $\alpha$. (B) HEK293T cells were transfected with FLAG-wt p85 $\alpha$, FLAG-Y607F p85 $\alpha$ or FLAG-Y607D p85, , +/- HAACK and then treated with cycloheximide (+) or DMSO (-). Cells were lysed, supernatants quantified for protein levels and equal amounts of lysate protein extracts were immunoprecipitated using an anti-p85 antibody. Levels of FLAG-p85 $\alpha$ variants were assessed by western blotting using an anti-FLAG antibody. All data is representative of at least three independent experiments.

Figure 8: Binding of the p85 $\mathrm{SH} 2$ domains to phosphopeptides. Purified $\mathrm{nSH} 2$ and cSH2 domains from $\mathrm{p} 85 \alpha$ and $\mathrm{p} 85 \beta$ were analysed for binding to synthetic phosphopeptides based on the sequences surrounding Tyr607 in p85 $\alpha$ and p85 $\beta$, in fluorescence polarization assays. Data from three independent experiments is shown with error bars represent standard deviation. (A) Binding of the $\mathrm{nSH} 2$ domain of $\mathrm{p} 85 \alpha$ to phosphorylated and non-phosphorylated peptides based on $\mathrm{p} 85 \alpha$ and $\mathrm{p} 85 \beta$. (B) Binding of the $\mathrm{nSH} 2$ domain of $\mathrm{p} 85 \beta$ to phosphorylated and non-phosphorylated 
peptides based on $\mathrm{p} 85 \alpha$ and $\mathrm{p} 85 \beta$. (C) Binding of the $\mathrm{cSH} 2$ domain of $\mathrm{p} 85 \alpha$ to phosphorylated peptides based on $\mathrm{p} 85 \alpha$ and $\mathrm{p} 85 \beta$, and a control peptide from CD28. (D) Binding of the $\mathrm{cSH} 2$ domain of $\mathrm{p} 85 \beta$ to phosphorylated peptides based on $\mathrm{p} 85 \alpha$ and $\mathrm{p} 85 \beta$, and a control peptide from CD28. (E) Binding of the wt $\mathrm{nSH} 2$ domain of $\mathrm{p} 85 \alpha$ and the R358M variant to phosphorylated peptides based on $\mathrm{p} 85 \alpha$ and $\mathrm{p} 85 \beta$. (F) Binding of the wt $\mathrm{nSH} 2$ domain of $\mathrm{p} 85 \beta$ and the $\mathrm{R} 358 \mathrm{M}$ variant to phosphorylated peptides based on $\mathrm{p} 85 \alpha$ and $\mathrm{p} 85 \beta$. (G) Ubiquitination of $\mathrm{p} 85 \alpha$. FLAG-p85 was expressed +/- Myc-Ubiquitin and +/- HA-ACK in HEK 293T cells. Cell lysates were immunoprecipitated with anti-FLAG antibody and then analysed by Western blotting with an anti-Myc antibody.

Figure 9: Subcellular localization of ACK, $\mathrm{p85} \alpha$ and the ACK-p85 $\alpha$ complex. (A) ACK and wt p85 $\alpha$ were expressed alone and together in HEK293T cells. Y607D p85 $\alpha$ and Y607F p85 $\alpha$ were expressed alone. Samples of whole cell lysates (WCL) were analysed by western blotting using the antibodies indicated and are shown in the left hand panels. Cells were lysed and separated into cytoplasmic and nuclearenriched fractions. Fractions were analysed by western blotting using the antibodies indicated (right hand panels). Fractionation was judged using anti-GAPDH to identify cytoplasmic extracts and anti-Histone $\mathrm{H} 3$ to identify nuclear-enriched fractions. The amount of p85 $\alpha$ variants found in the cytoplasmic and nuclear-enriched fractions were analysed by densitometry using Image J. The total amount of $\mathrm{p} 85$ was normalized to 100 and the fractions expressed as a percentage of total. wt p85 $\alpha$ expressed alone was distributed 7:93 cytoplasmic (C):nuclear $(\mathrm{N})$; p85 $\alpha$ co-expressed with ACK, 46:54; p85 $\alpha$ Y607F 50:50 and p85 $\alpha$ Y607D, 30:70. (B) Top panels: FLAG-p85 $\alpha$ was immunoprecipitated from nuclear-enriched and cytoplasmic fractions using an antiFLAG antibody. Immunoprecipitation of FLAG-p85 $\alpha$ and co-immunoprecipitation of HA-ACK was assessed by western blotting using anti-FLAG and anti-HA antibodies. Bottom panels: Expression of FLAG-p85 $\alpha$ and HA-ACK along with active ACK levels was confirmed by western blotting of whole cell lysate (WCL) samples collected prior to cell fractionation. All data is representative of at least three independent experiments.

Figure 10: Dimerization of the regulatory subunits. (A) wt p $85 \beta$ and wt p50 $\alpha$ were expressed alone or co-expressed in HEK293T cells. Samples of whole cell lysates (WCL) were analysed by western blotting using the antibodies indicated and are shown in lower panels. p50 $\alpha$ was immunoprecipitated from cell lysates using an antiFLAG antibody and the co-immunoprecipitation of $\mathrm{p} 85 \beta$ was assessed using an antiV5 antibody (top panels). Results are representative of at least three independent experiments. (B) wt p $85 \beta$ and wt $\mathrm{p} 85 \alpha$ were expressed alone or co-expressed in HEK293T cells. Samples of whole cell lysates (WCL) were analysed by western blotting using the antibodies indicated and are shown in lower panels. p85 $\alpha$ was immunoprecipitated from cell lysates using an anti-FLAG antibody and the coimmunoprecipitation of $\mathrm{p} 85 \beta$ was assessed using an anti-V5 antibody (top panels). Results are representative of at least three independent experiments. (C) wt p85 $\beta$, wt p50 $\alpha$ and Y307D p50 $\alpha$ were expressed alone or co-expressed in HEK293T cells. Samples of whole cell lysates (WCL) were analysed by western blotting using the antibodies indicated and are shown in lower panels. p50 $\alpha$ variants were immunoprecipitated from cell lysates using an anti-FLAG antibody and the co- 
immunoprecipitation of $\mathrm{p} 85 \beta$ was assessed using an anti-V5 antibody (top panels). Results are representative of at least three independent experiments.

\section{Figure 11: Subcellular localization of the nSH2-pTyr607 regulatory subunit}

dimers. wt p85 $\beta$, wt p85 $\alpha$ and wt p50 $\alpha$ were expressed alone or together in HEK293T cells. Cells were lysed and separated into cytoplasmic and nuclear-enriched fractions. Fractions were analysed by western blotting using the antibodies indicated (lower panels). Fractionation was judged using anti-GAPDH to identify cytoplasmic extracts and anti-Histone $\mathrm{H} 3$ to identify nuclear-enriched fractions. p50 $\alpha$ or p85 $\alpha$ were immunoprecipitated from cell lysates using an anti-FLAG antibody and the coimmunoprecipitation of $\mathrm{p} 85 \beta$ was assessed using an anti-V5 antibody (top panels). Results are representative of at least three independent experiments.

Figure 12: Structural model of the novel nSH2-pTyr607 mediated dimers. The model was constructed in Pymol using the following PDB codes: SH3 domain, 3i5r; BCR domain, 1pbw; nSH2-iSH2, 4123; cSH2 5aul. The SH3, BH and nSH2 domains were rotated to minimize the distance between $\mathrm{C}$ - and $\mathrm{N}$-terminal residues in adjacent domains. Domains were moved into one plane for clarity. The $\mathrm{cSH} 2$ was then positioned as follows: PDB 2iuh (p85 SH2 in complex with a c-Kit peptide) was aligned onto the model and the peptide component was mutated to the $\mathrm{p} 85$ sequence. The linker between the end of the iSH2 structure and the start of the peptide is 6 residues but there is no linker at all between the end of the peptide and the SH3 domain. When the iSH2 and SH3 domains were moved to be correctly positioned for the peptide to interact with the $\mathrm{nSH} 2$ it was not possible for an intramolecular $\mathrm{nSH} 2$ peptide interaction without steric clashes. A second monomer was constructed and the $\mathrm{nSH} 2$-peptide interaction used to derive the approximate positions of the domains in a dimer. (A) The potential p $85 \alpha$ homodimer. The two chains of the dimer are shown in blue and red, with pale shades at the $\mathrm{N}$-terminus and darker shades at the $\mathrm{C}$-terminus. The domains are linked by dotted lines and the $\mathrm{G}$ protein binding site of the $\mathrm{BH}$ domain is indicated by a green circle. (B) The potential p $85 \alpha-p 50 \alpha$ heterodimer, colours as above except that $\mathrm{p} 50$ is red and p85 is blue. (C) Close up view showing the details of the intermolecular interaction between pTyr607 (blue) and the nSH2 (red). The sidechain of Tyr607 is shown as blue sticks and the phosphate group as a yellow sphere.

Figure 13: Model depicting the multiple roles of ACK in the regulation of PI3Kinase signalling. ACK interacts with the PI3-Kinase regulatory subunit(s) (p85) in the nucleus, phosphorylating Tyr607. This leads to stabilization of p85 levels by preventing ubiquitination and subsequent degradation by the proteasome. Increased levels of p85 and pY607 promote dimerization of the regulatory subunits. We propose that this new dimeric conFigureuration of the regulatory subunits possesses proproliferative nuclear functions. The interaction between ACK and the regulatory subunits ultimately leads to a suppression PIP $_{3}$ levels in the cell, however, ACK is able to promote cell proliferative signals by phosphorylating Akt, contributing to its activation. PDK1: Phosphoinositide-dependent kinase-1, mTORC2: mTOR complex 2, PTEN: phosphatase and tensin homologue, PA: phosphatidic acid. 
Regulation of the PI3-Kinase regulatory subunits by $A C K$

\section{Supplementary Material}

Figure S1: Identification of ACK phosphorylation sites in GST-p50 $\alpha$. (A) GST-p50 $\alpha$ is phosphorylated on Y307 by His6-ACK (110-489) in vitro. Full-length GST-p50 $\alpha$ was purified from $E$. coli and incubated at $30^{\circ} \mathrm{C}$ for 30 minutes with His6-ACK (110489) purified from Sf9 cells. Reactions were analysed by SDS-PAGE and the phosphorylation of GST-p50 $\alpha$ at Y307 was assessed by western blotting using an antibody raised against the sequence (D-Q-Y(p)-S-L) in human $\mathrm{p} 85 \alpha$. The presence of autophosphorylated His6-ACK (110-489) was confirmed by western blotting using an anti-ACK (pY284) antibody. (B) In vitro kinase assay reactions for GST-p50 $\alpha$ in the presence and absence of His6-ACK (110-489) were resolved on a NuPAGE 4-12\% gel and proteins were visualized by Coomassie staining. (C) Phosphorylation sites in excised full-length GST-p50 $\alpha$ (red box, panel B) were identified by LC-MS/MS. Annotated MS/MS spectrum of the tyrosine phosphorylated peptide KLNEWLGNENTEDQYSLVEDDEDLPHHDEK (m/z 923.65, 4+). The doubly charged C-terminal y fragment ions are highlighted which specifically represent the tyrosine phosphorylation. This can be compared with the non-phosphorylated peptide (D) $(\mathrm{m} / \mathrm{z} 903.65,4+)$ in which the $\mathrm{m} / \mathrm{z}$ values are 40 units lower (corresponding to a mass of $80 \mathrm{Da}$ ) from y16, which is indicative of tyrosine phosphorylation.

Figure S2: (A) wt p50 $\alpha$ and wt p55 $\gamma$ were expressed alone or co-expressed with ACK in HEK293T cells. Cells were lysed and separated into cytoplasmic and nuclearenriched fractions. Fractions were analysed by western blotting using the antibodies indicated (left hand panels). Fractionation was judged using anti-Hsp56 to identify cytoplasmic extracts and anti-Histone $\mathrm{H} 3$ to identify nuclear-enriched fractions. Samples of whole cell lysates (WCL) were analysed by western blotting, to show total levels of proteins, using the antibodies indicated and are shown in the right hand panels. Results are representative of at least three independent experiments. (B) wt p85 $\alpha$ and Y607F p85 $\alpha$ were expressed alone or co-expressed with ACK in HEK293T cells. Cells were lysed and separated into cytoplasmic and nuclear-enriched fractions. Fractions were analysed by western blotting using the antibodies indicated (left hand panels). Fractionation was judged using anti-Hsp56 to identify cytoplasmic extracts and anti-Histone $\mathrm{H} 3$ to identify nuclear-enriched fractions. Samples of whole cell lysates (WCL) were analysed by western blotting, to show total levels of proteins, using the antibodies indicated and are shown in the right hand panels. Results are representative of at least three independent experiments. 


\section{Figure 1}

A

$1-489$

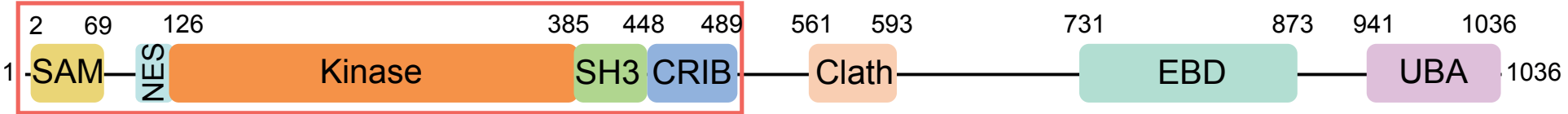

B

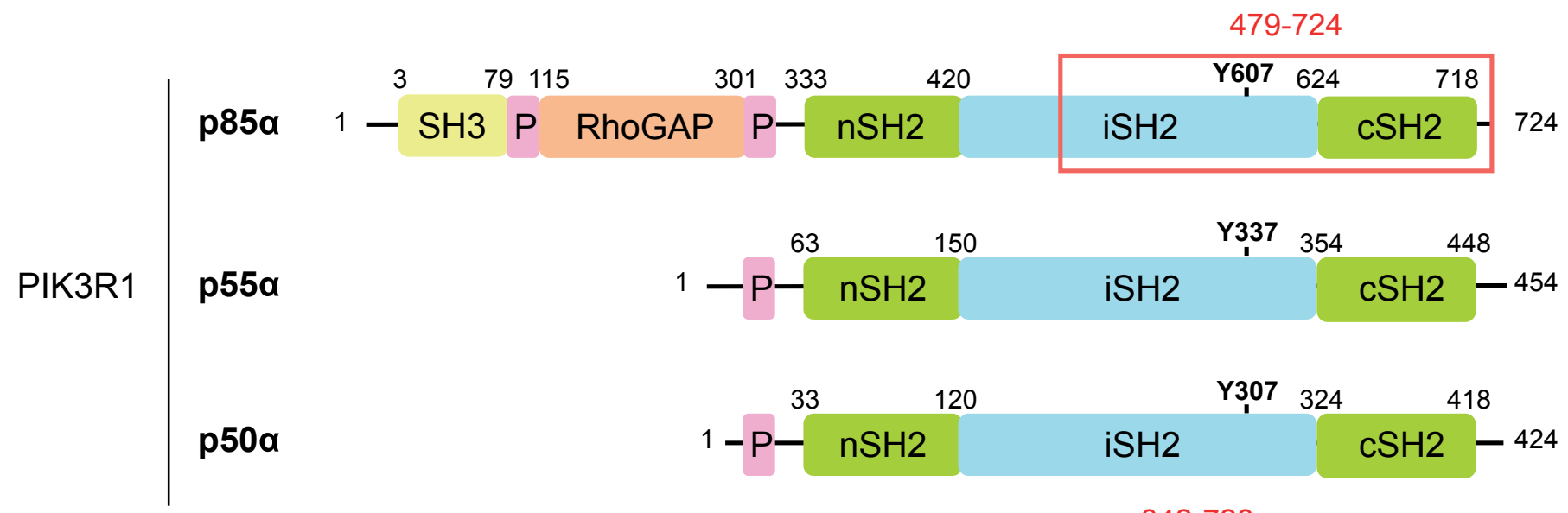

$342-728$

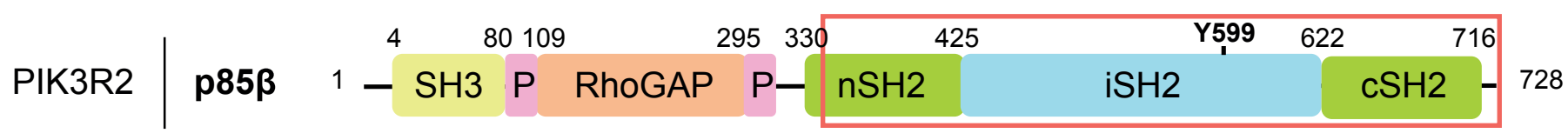

120-461

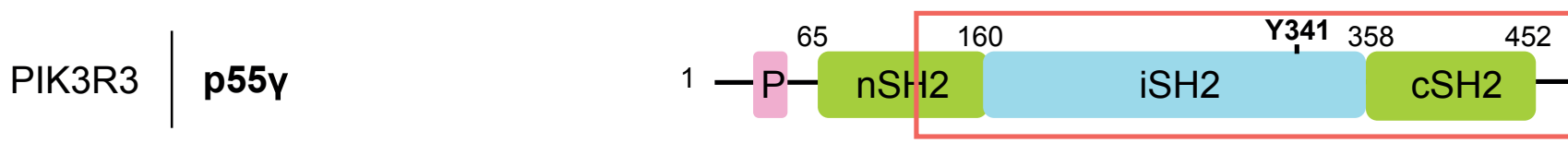




\section{Figure 2}
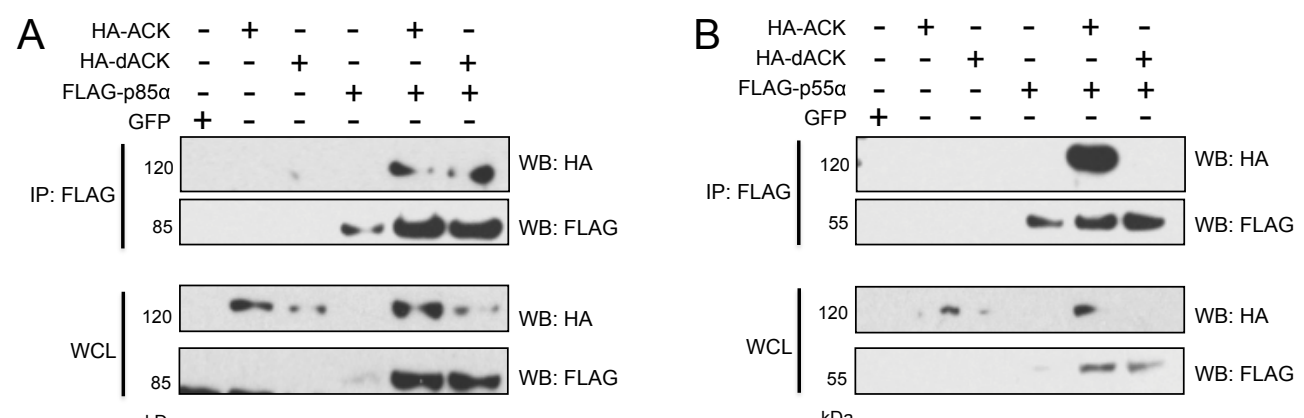

$\mathrm{kDa}$

$\mathrm{kDa}$
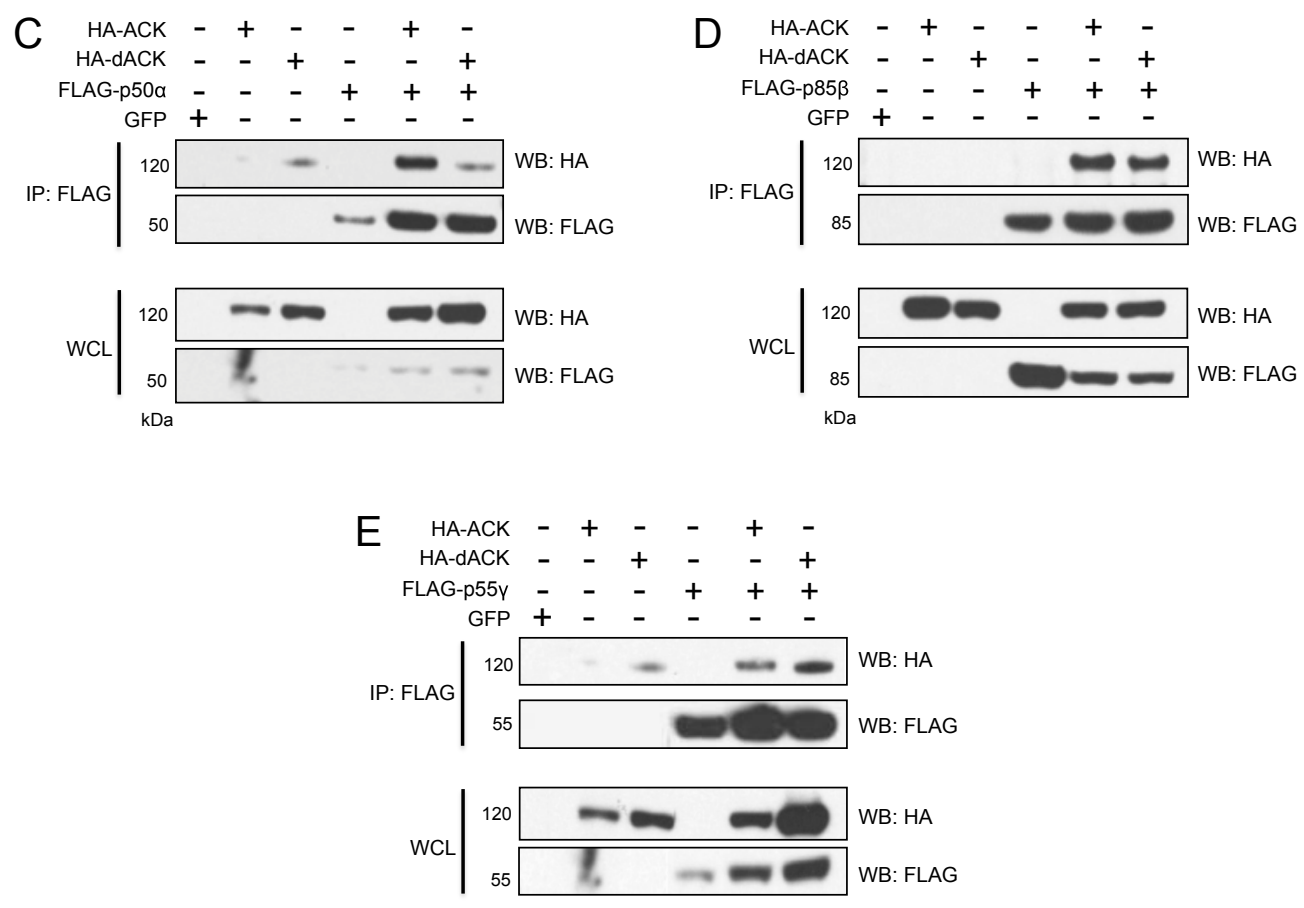

$\mathrm{kDa}$ 


\section{Figure 3}
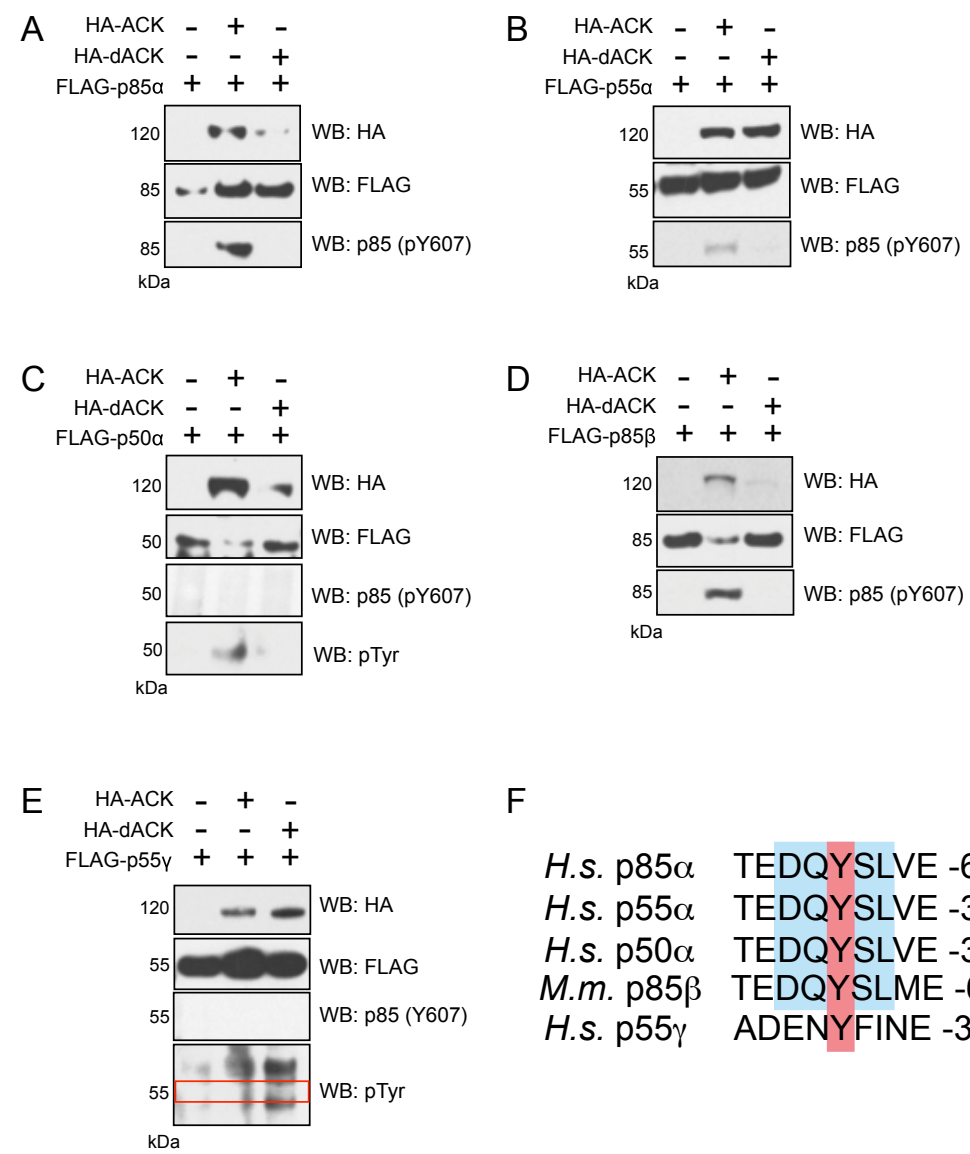

$\mathrm{F}$

H.s. p85 $\alpha$ TEDQYSLVE -611

H.s. p55 $\alpha$ TEDQYSLVE -341

H.s. p50 $\alpha$ TEDQYSLVE -311

M.m. p85 $\beta$ TEDQYSLME -603

H.s. p55 $\gamma$ ADENYFINE -345 
bioRxiv preprint doi: https://doi.org/10.1101/791277; this version posted October 4, 2019. The copyright holder for this preprint (which was

not certified by peer review) is the author/funder, who has granted bioRxiv a license to display the preprint in perpetuity. It is made available under aCC-BY 4.0 International license.

\section{Figure 4}

A

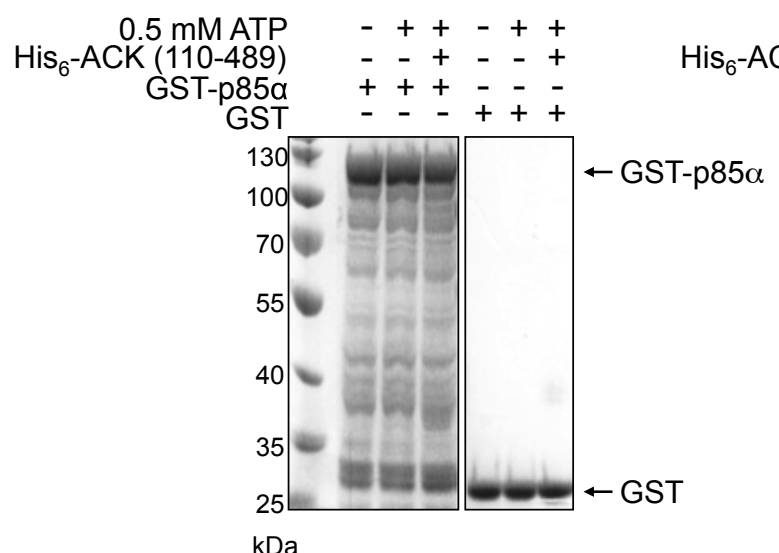

$0.5 \mathrm{mM} \mathrm{ATP}-++\quad++$

$(110-489)--+-+$

GST-p85a $+ \pm+\div+$

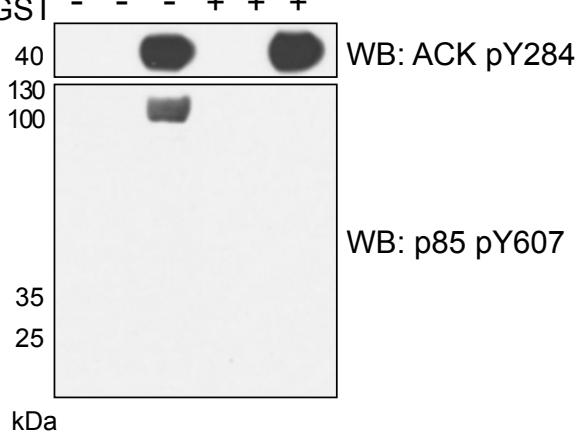

B

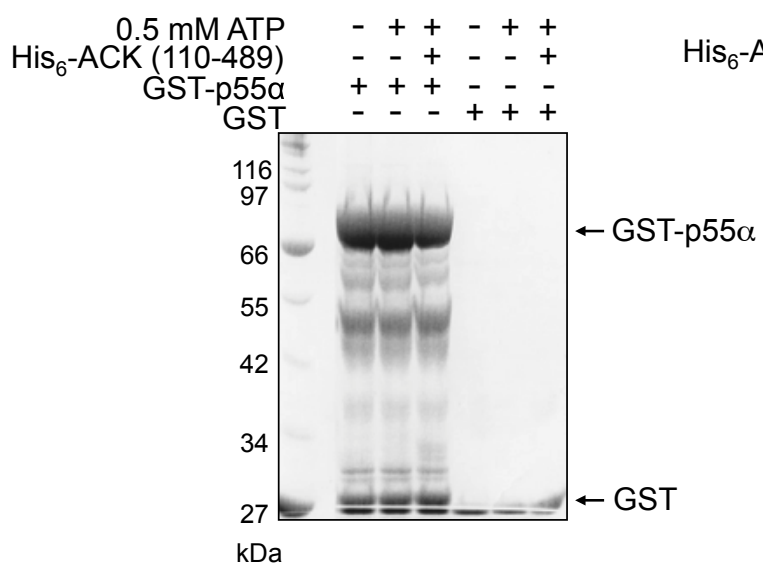

$0.5 \mathrm{mM} \mathrm{ATP}-++\quad++$

$(110-489)-++-+$

GST-p55 + + + + + +

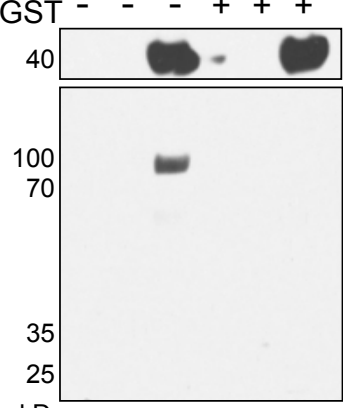

WB: ACK pY284

WB: p85 pY607

$\mathrm{kD}$

$\mathrm{kDa}$

C

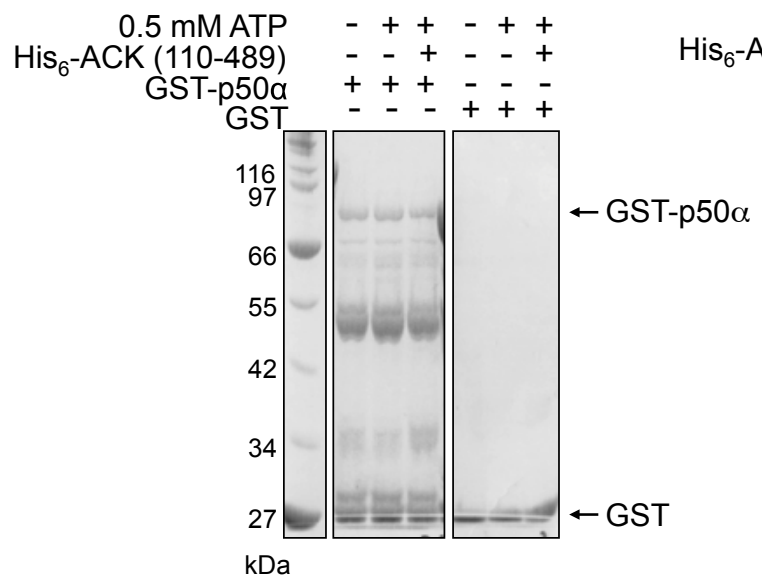

0.5 mM ATP -++-++

GST-P5OA $+-\overline{+}+$

GST - \pm++

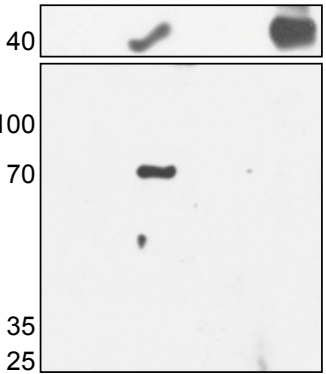

WB: ACK pY284

(Da

$\mathrm{kDa}$

D

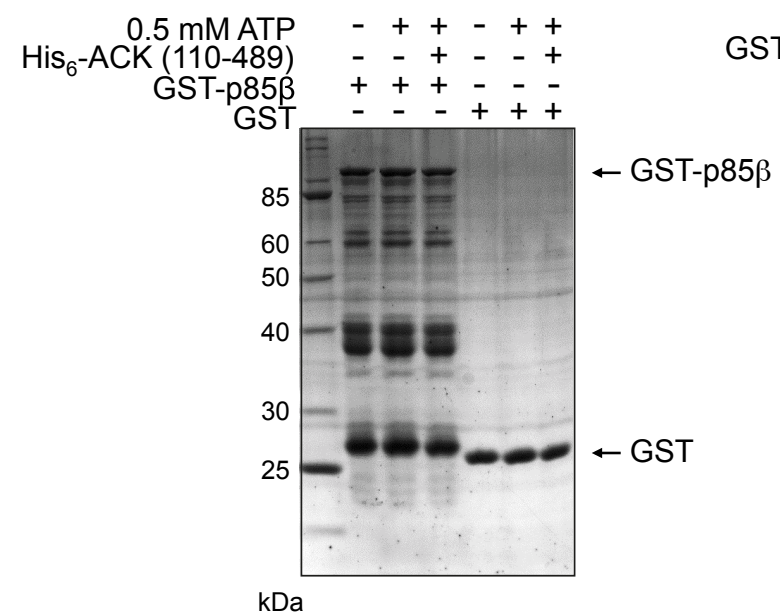

$0.5 \mathrm{mM} \mathrm{ATP}-++++$

GST-ACK (1-489) - - + - +

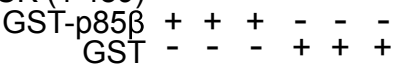

WB: p85 pY607

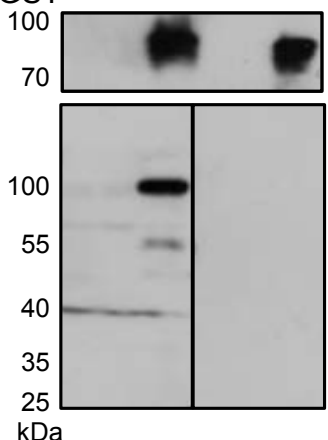

WB: ACK pY284

WB: p85 pY607

$\mathrm{kDa}$ 


\section{Figure 5}
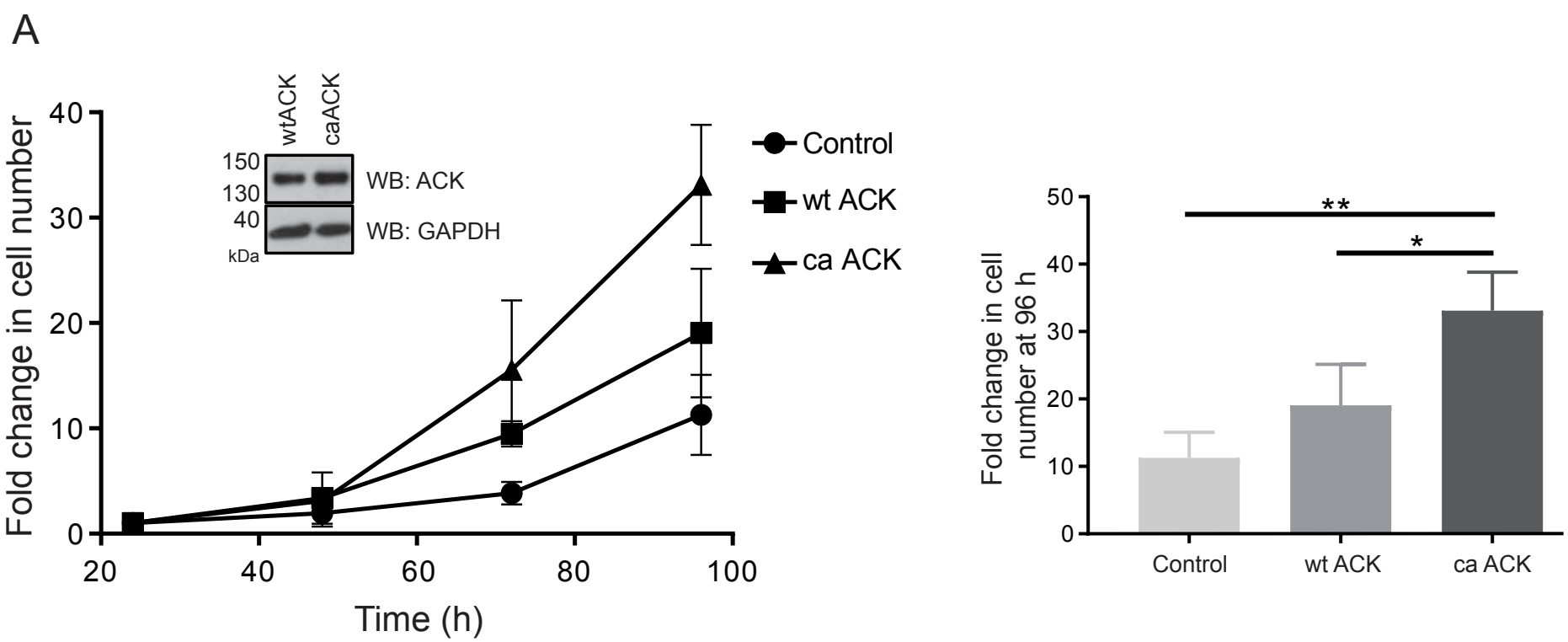

B
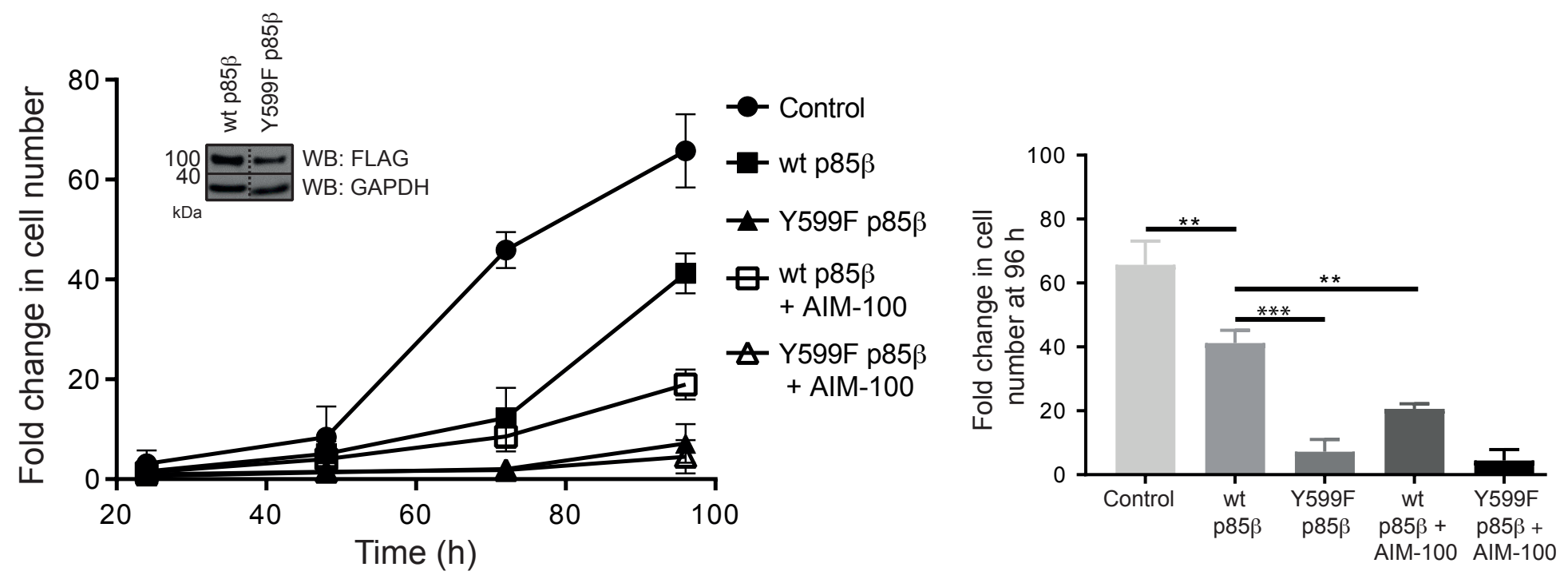


\section{Figure 6}

A

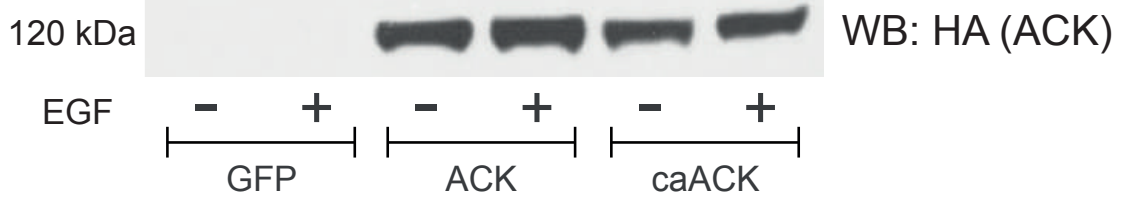

B

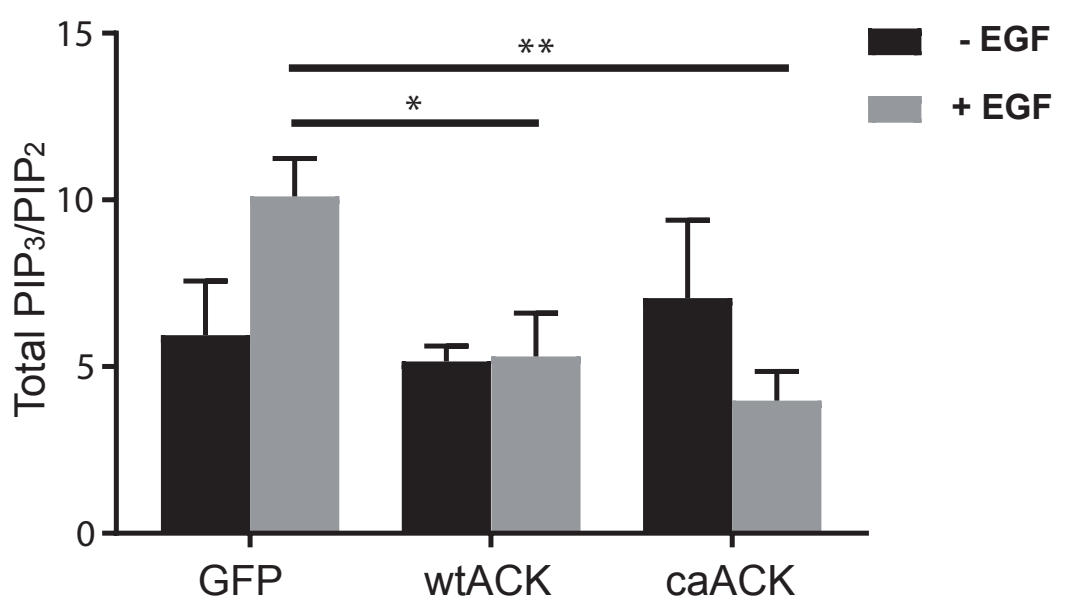




\section{Figure 7}

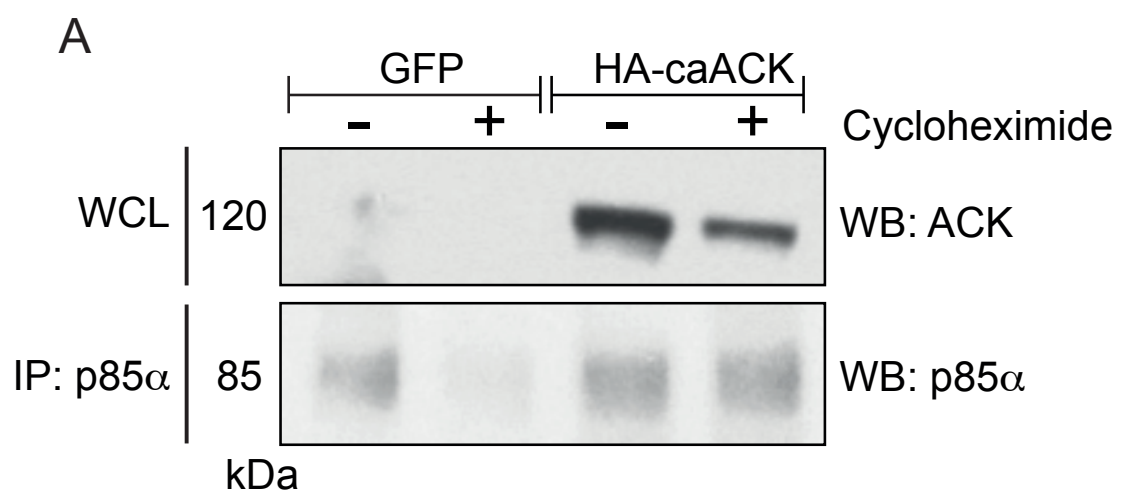

B

FLAG-wt p85 $\alpha++\quad+\quad+$ FLAG-Y607F p85 $\alpha$ $+++$

FLAG-Y607D p85 $\alpha$

$$
\text { HA-ACK }
$$

Cycloheximide
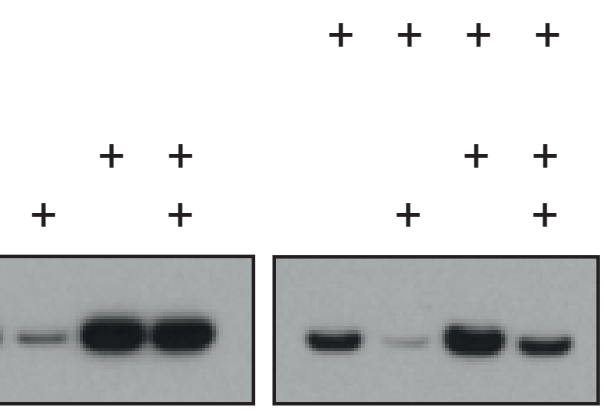
$++++$
$++$
$+\quad+$

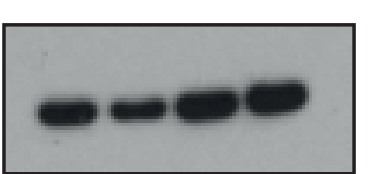

WB:FLAG

$\mathrm{kDa}$ 


\section{Figure 9}

\section{A}

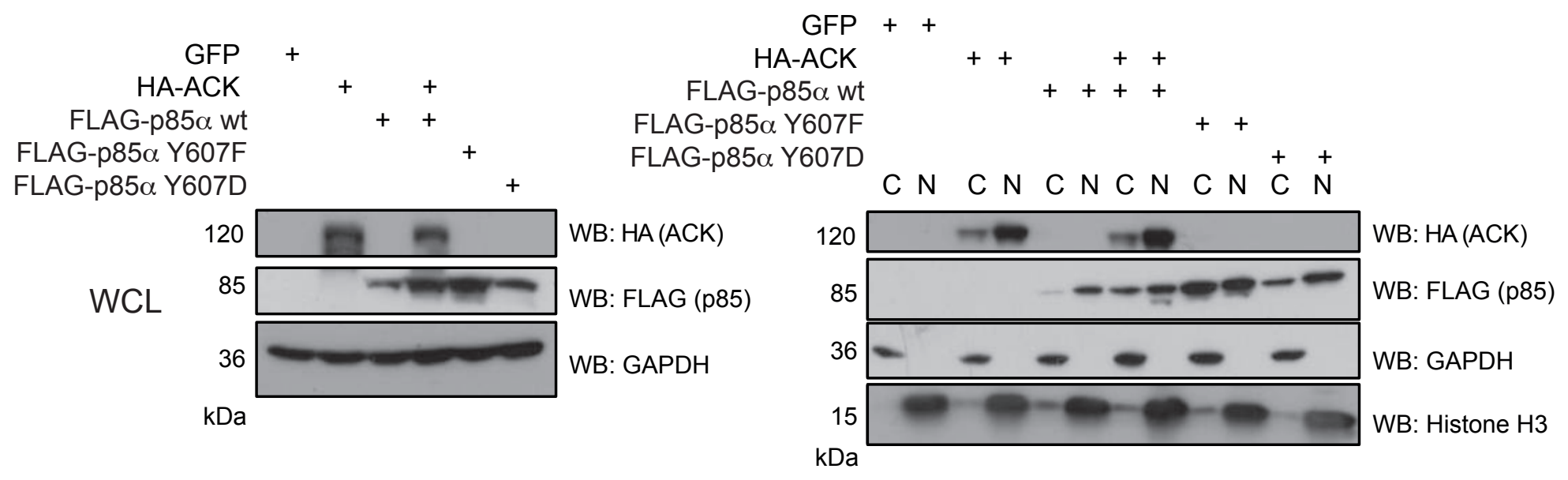

B

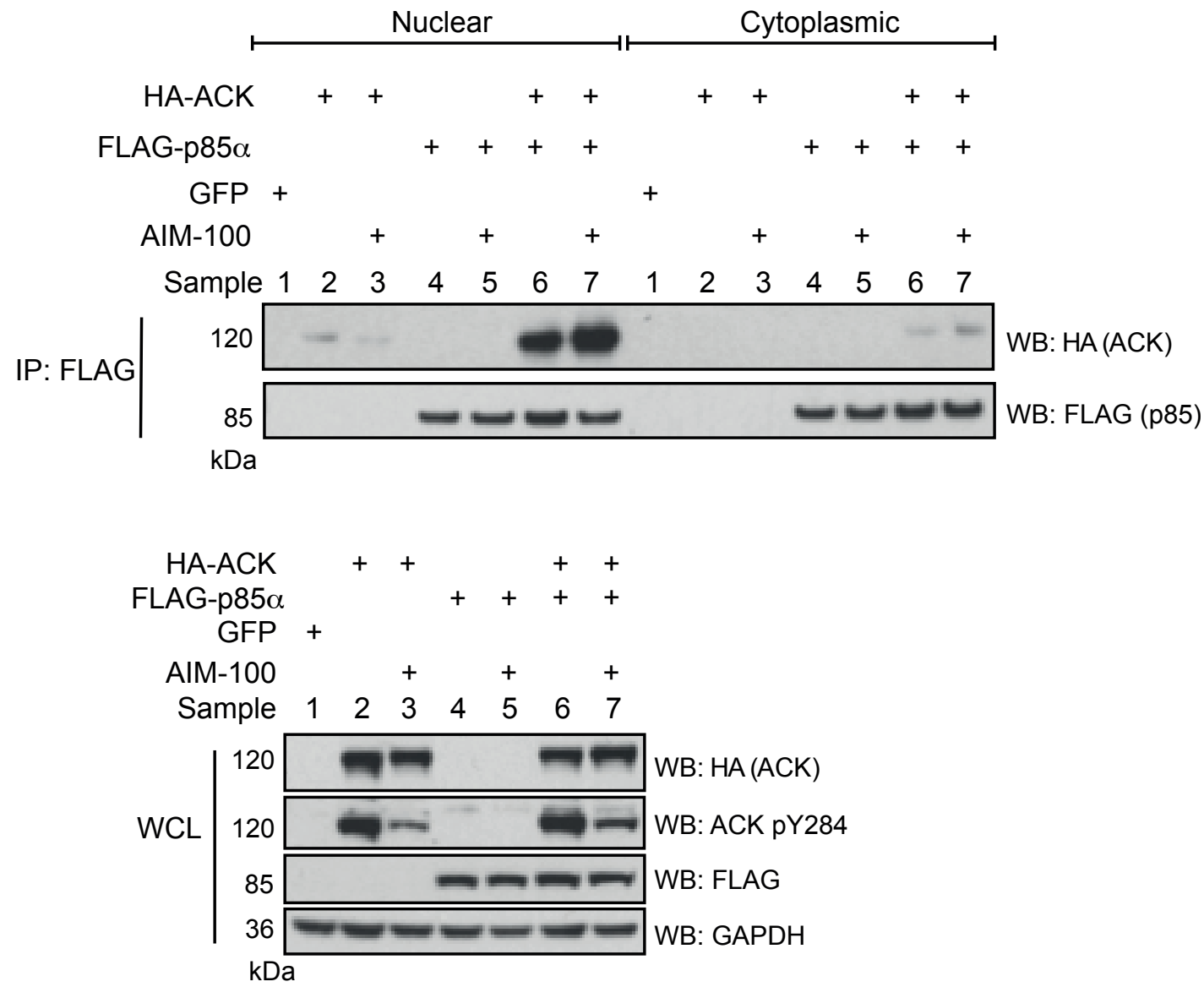


bioRxiv preprint doi: https://doi.org/10.1101/791277; this version posted October 4, 2019. The copyright holder for this preprint (which was

not certified by peer review) is the author/funder, who has granted bioRxiv a license to display the preprint in perpetuity. It is made available under aCC-BY 4.0 International license.

\section{Figure 10}

A

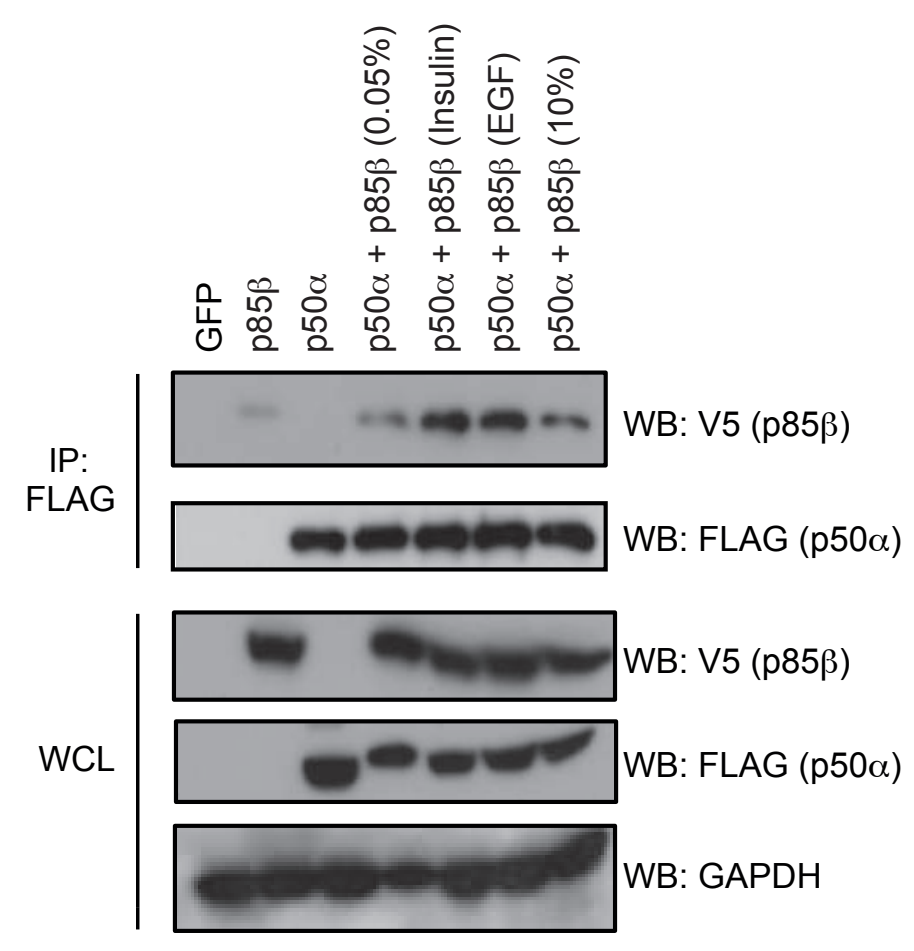

B

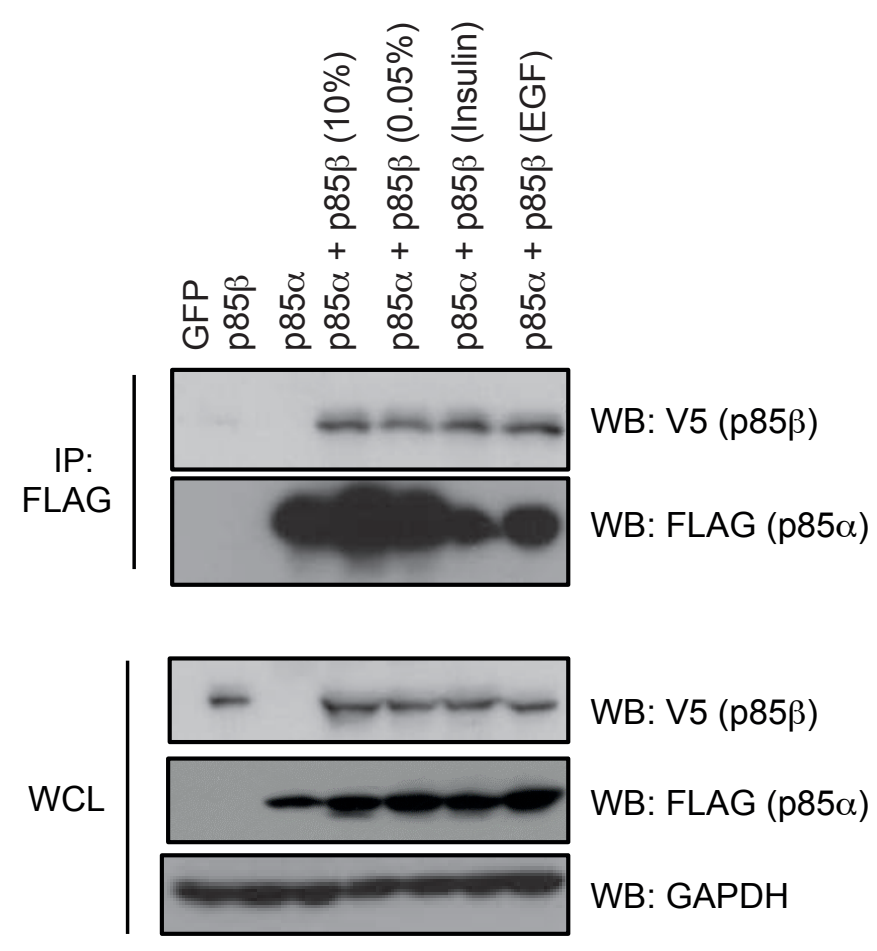

C

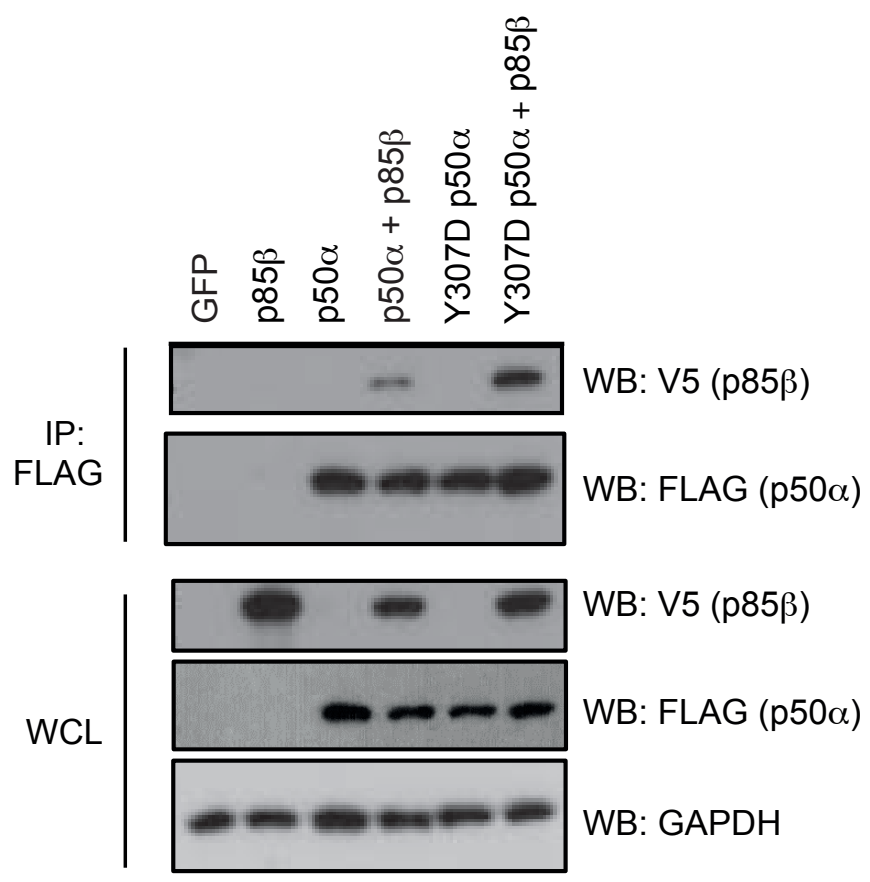




\section{Figure 11}

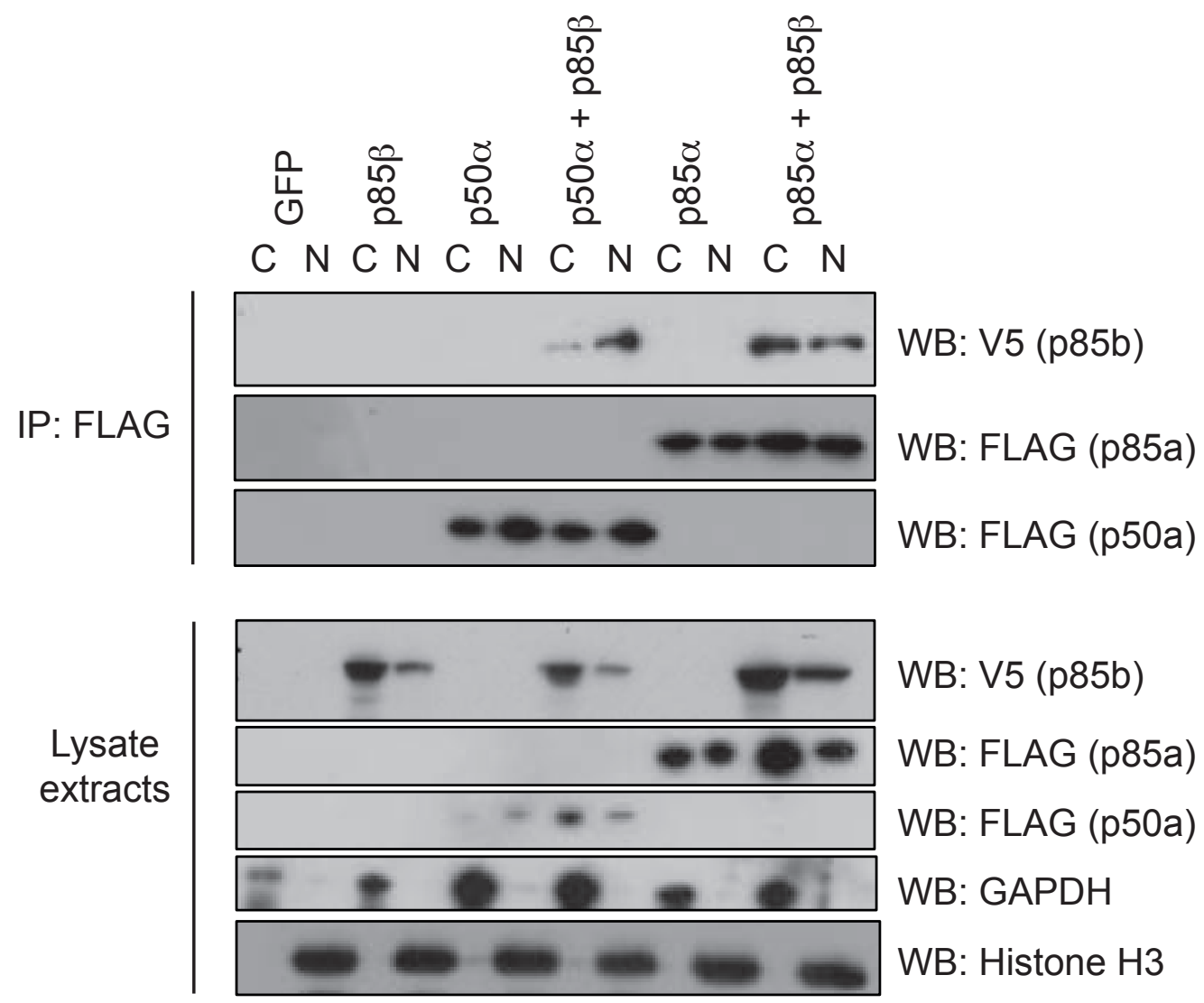


bioRxiv preprint doi: https://doi.org/10.1101/791277; this version posted October 4, 2019. The copyright holder for this preprint (which was

not certified by peer review) is the author/funder, who has granted bioRxiv a license to display the preprint in perpetuity. It is made available under aCC-BY 4.0 International license.

Figure 12

A

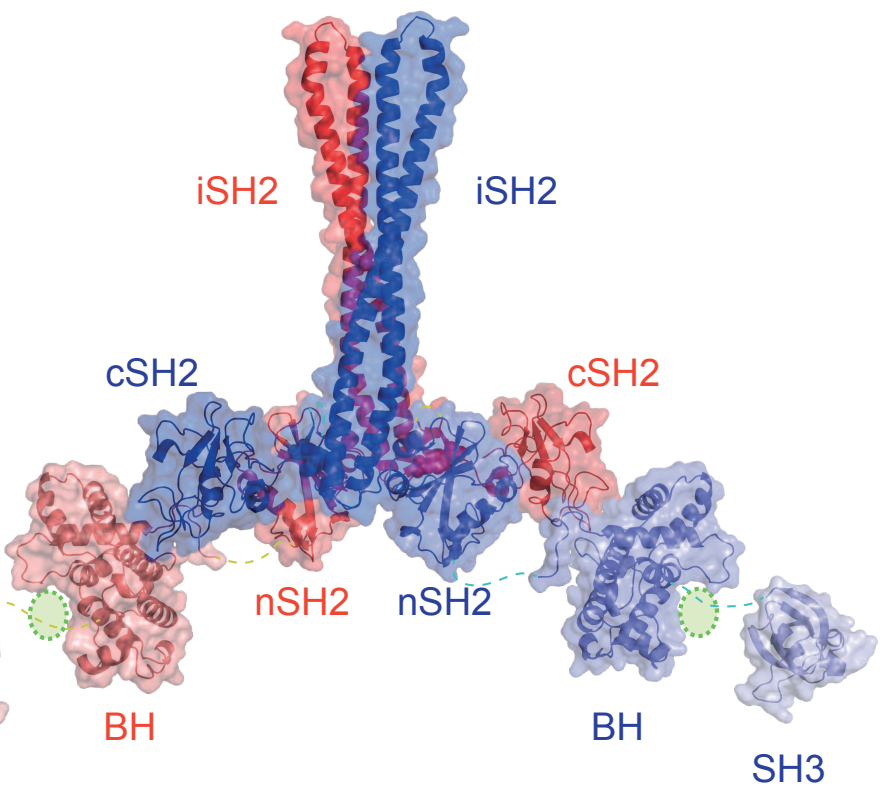

B

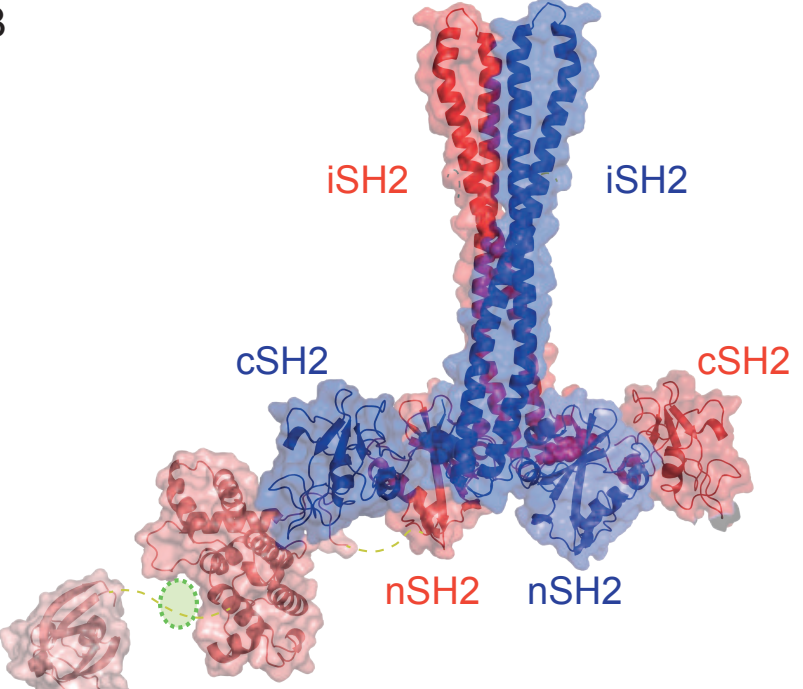

$\mathrm{BH}$

$\mathrm{SH} 3$

C

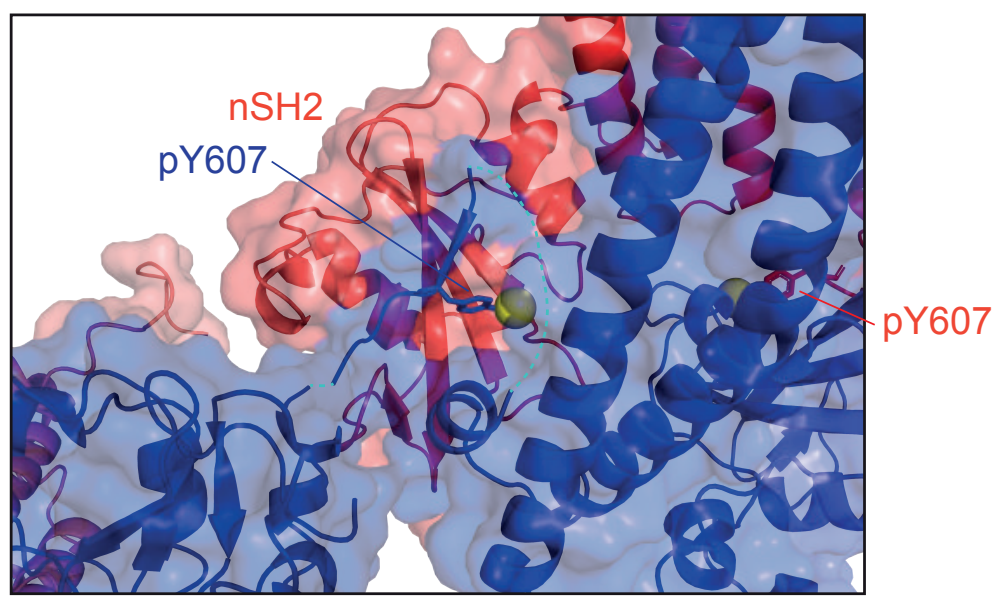




\section{Figure 13}

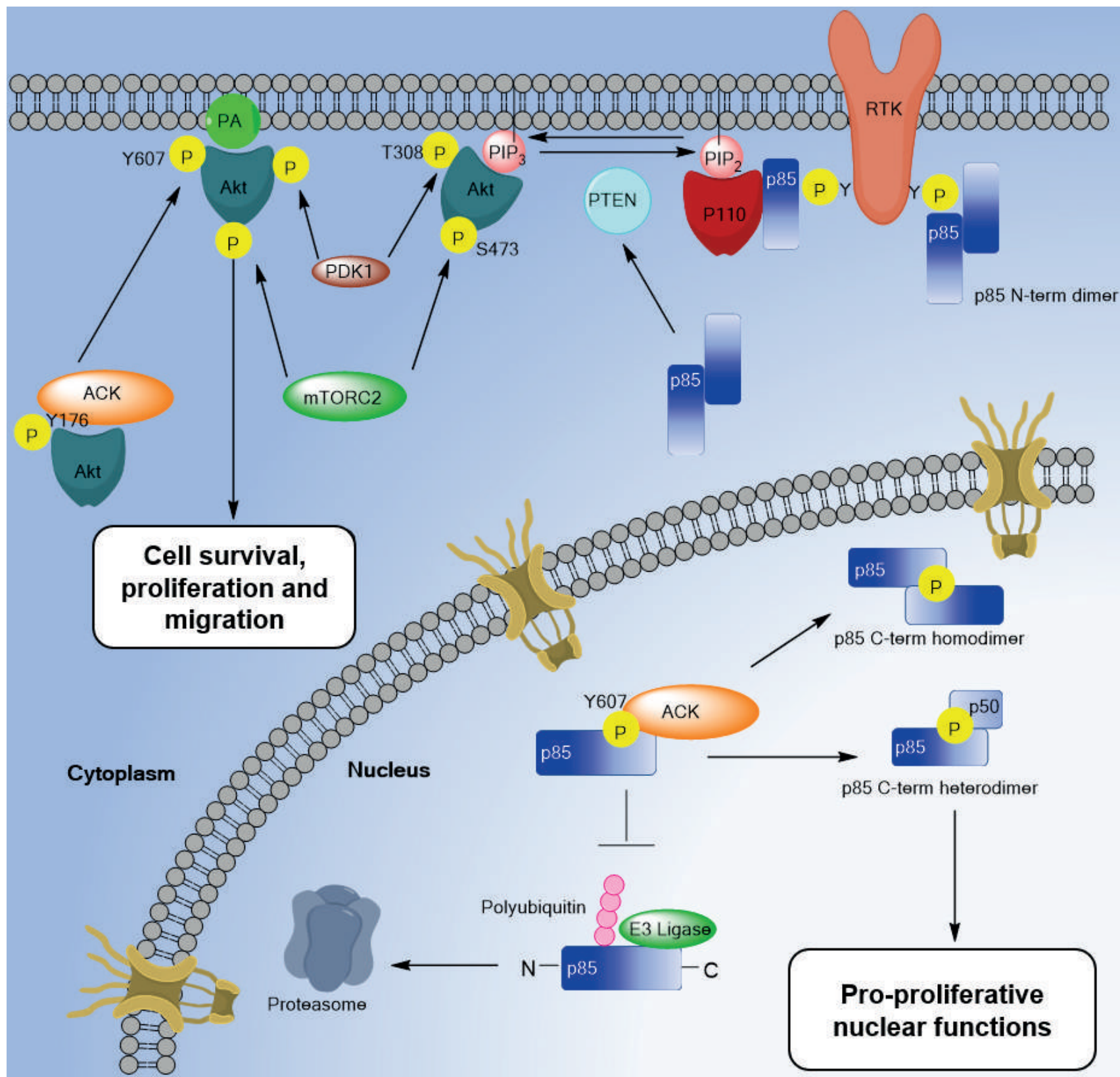


A

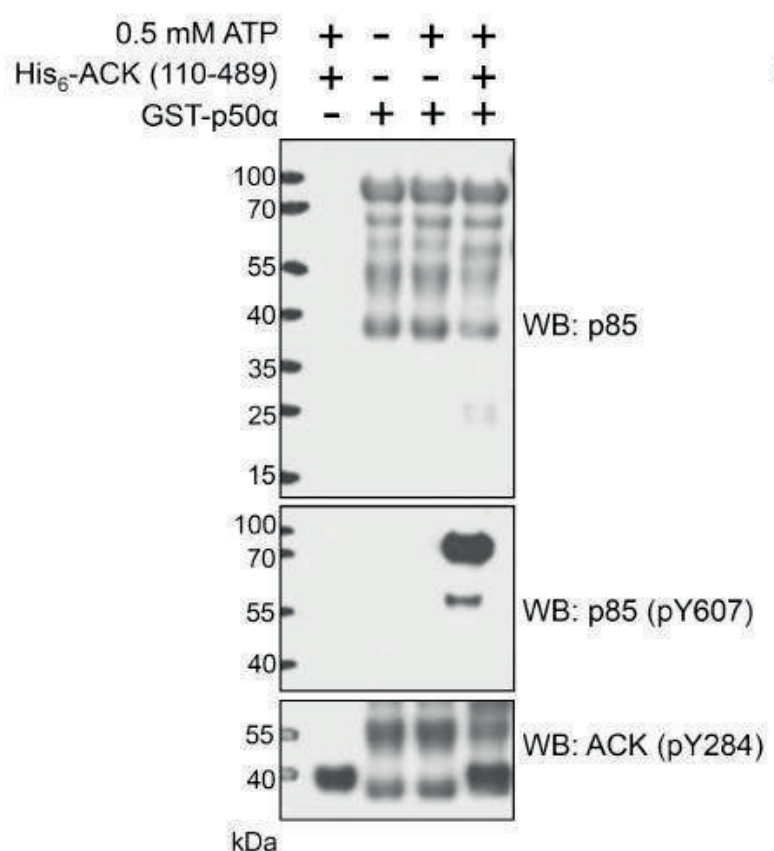

B

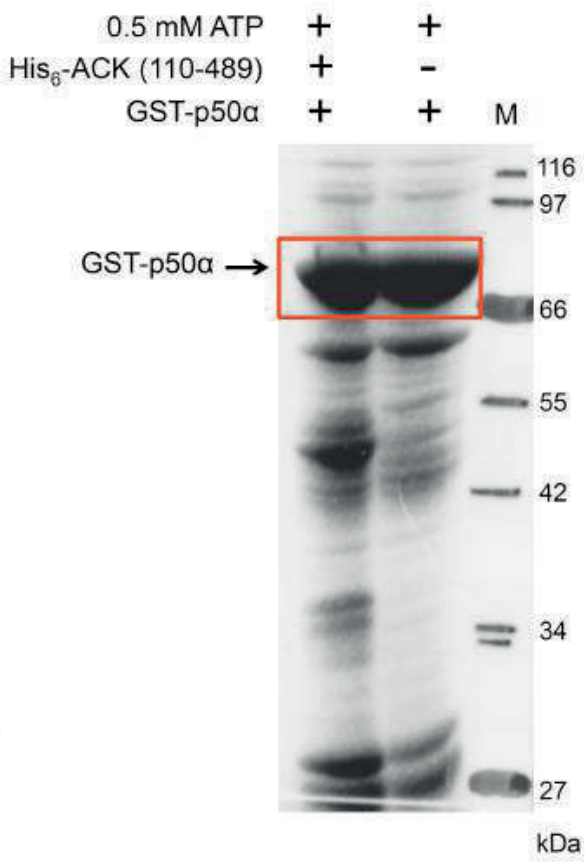

C

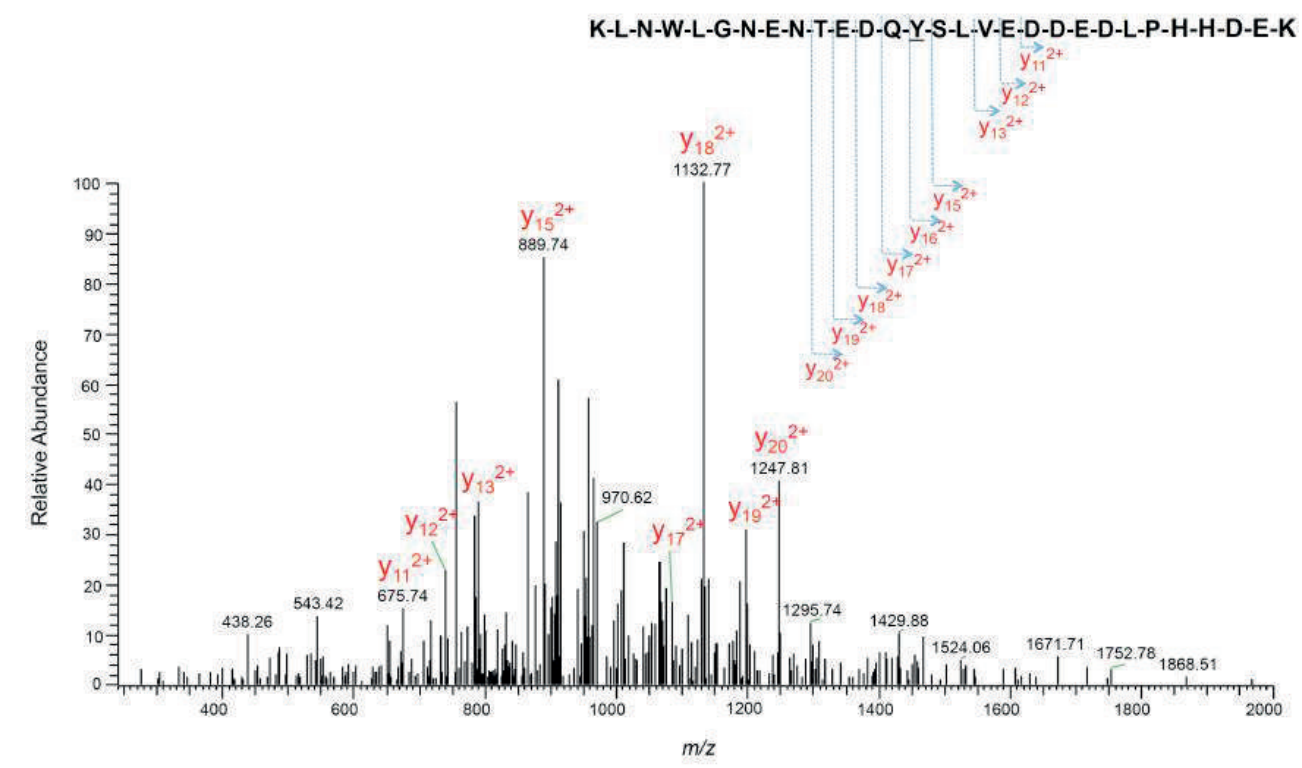

D

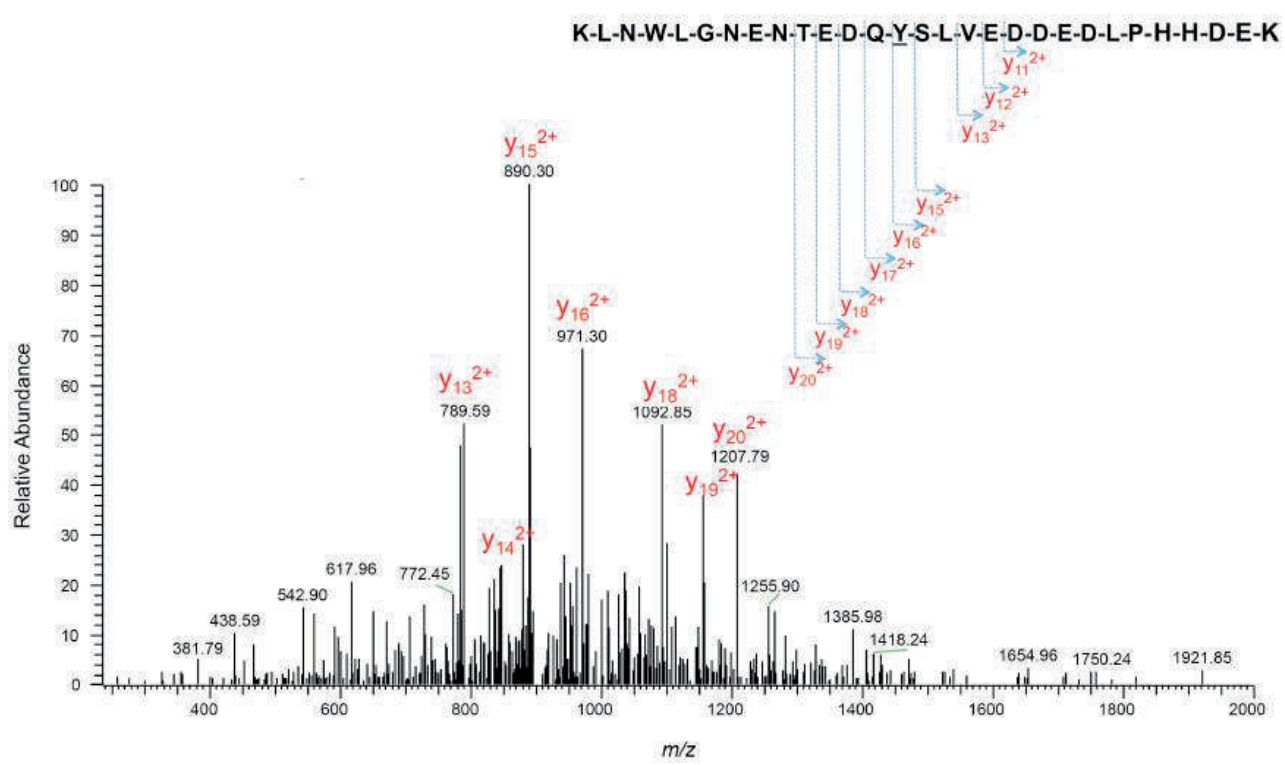




\section{Figure S2}

A

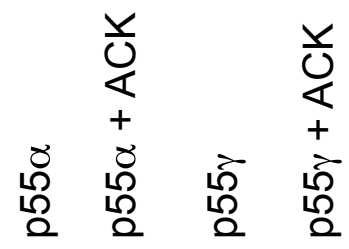

C N C N C N C N

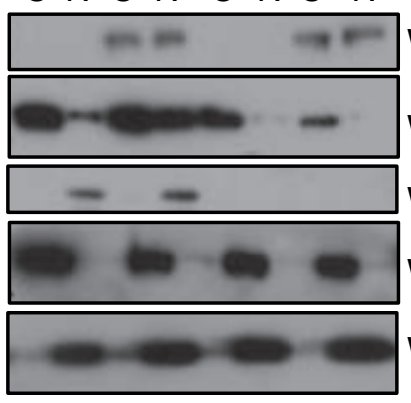

WB: ACK

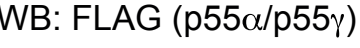

WB: pY607

WB: Hsp56

WB: Histone $\mathrm{H} 3$

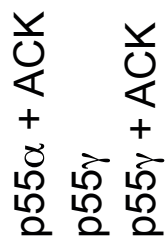

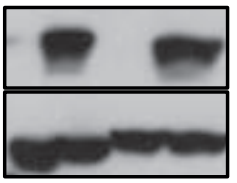

WB: ACK

WB: FLAG $(p 55 \alpha / p 55 \gamma)$

WCL

B

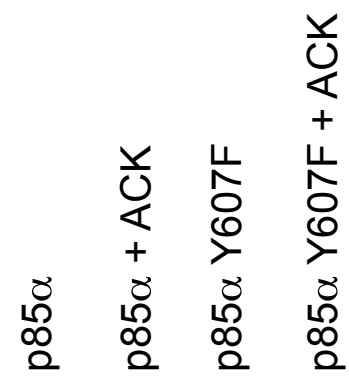

$C N C N C N C N$

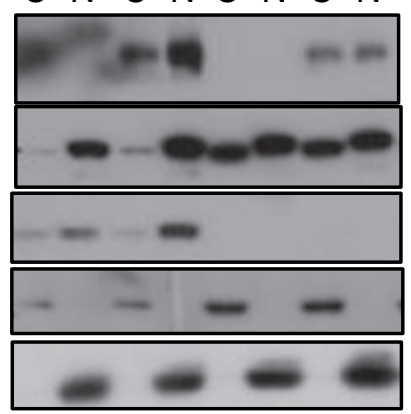

WB: ACK

WB: FLAG $(p 85 \alpha)$

WB: pY607

WB: Hsp56

WB: Histone $\mathrm{H} 3$

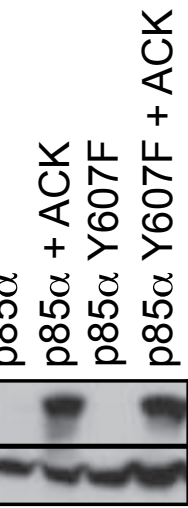

WB: ACK

WB: FLAG $(p 85 \alpha)$

WCL 